GLOBAL WATER PATHOGEN PROJECT

PART THREE. SPECIFIC EXCRETED PATHOGENS: ENVIRONMENTAL AND EPIDEMIOLOGY ASPECTS

\title{
ECHINOCOCCUS SPP.
}

\section{Dominique Vuitton}

Universite de Franche-Comte

Besançon, France

\section{Wenbao Zhang}

First Affiliated Hospital of Xinjiang Medical University

Ürümqi, China

\section{Patrick Giraudoux}

Université de Bourgogne Franche-Comté

Dijon, France 


\section{Copyright:}

\section{cc) (i) (2) \\ BY SA}

This publication is available in Open Access under the Attribution-ShareAlike 3.0 IGO (CC-BY-SA 3.0 IGO) license (http://creativecommons.org/licenses/by-sa/3.0/igo). By using the content of this publication, the users accept to be bound by the terms of use of the UNESCO Open Access Repository (http://www.unesco.org/openaccess/terms-use-ccbysa-en).

\section{Disclaimer:}

The designations employed and the presentation of material throughout this publication do not imply the expression of any opinion whatsoever on the part of UNESCO concerning the legal status of any country, territory, city or area or of its authorities, or concerning the delimitation of its frontiers or boundaries. The ideas and opinions expressed in this publication are those of the authors; they are not necessarily those of UNESCO and do not commit the Organization.

\section{Citation:}

Vuitton, D., Zhang, W. and Giraudoux, P. (2017). Echinococcus spp. In: J.B. Rose and B. Jiménez-Cisneros (eds), Water and Sanitation for the 21st Century: Health and Microbiological Aspects of Excreta and Wastewater Management (Global Water Pathogen Project). (L. Robertson (eds), Part 3: Specific Excreted Pathogens: Environmental and Epidemiology Aspects - Section 4: Helminths), Michigan State University, E. Lansing, MI, UNESCO. https://doi.org/10.14321/waterpathogens.39

Acknowledgements: K.R.L. Young, Project Design editor; Website Design (http://www.agroknow.com)

Last published: December 19, 2017 


\section{Summary}

The tapeworms and their eggs are a risk to humans from dog feces thus the role of human excreta or sewage is generally not of concern. However due to the association with animals, particular dog excreta is an issue regarding hygiene and soil contamination where dogs are infected.

The larval stages (metacestodes) of the helminth cestodes of the genus Echinococcus are the causes of echinococcoses. Until recently, the main two species recognized to cause diseases in humans were respectively E. granulosus, for 'cystic echinococcosis' (CE, formerly named 'hydatidosis', or 'hydatid disease' or 'hydatid cyst'), and E. multilocularis, for alveolar echinococcosis (AE). The estimated minimum global human burden of human CE averages 285,500 disability-adjusted life years (DALYs) (more than 1 million if underreporting is taken into account), and $\mathrm{AE}$, a rare but more severe disease, results in a median of 666,434 DALYs per year. At the beginning of the 21 st century, based on genetic characteristics, E. granulosus sensu lato has been split into several species: $E$. granulosus sensu stricto (ex-sheep strain), E. felidis, E. equinus (ex-horse strain), E. ortleppi (ex-cattle strain), and E. canadensis (ex-camel, pig and cervid strains). E. oligarthrus and E. vogeli (only present in South America) cause diseases with a clinical presentation similar to that of $\mathrm{CE}$ and $\mathrm{AE}$, respectively.

The metacestodes consist of the germinal layer surrounded by the laminated layer. The germinal layer forms 'buds', then 'vesicles' (cysts), which are filled with a water-like liquid ('hydatid/cyst/vesicle fluid'). Cysts may be single with little inflammatory reaction (typically for $\mathrm{CE}$ ) or multiple and aggregated with an impressive granulomatous infiltrate, dense fibrosis, and necrosis of the central part of lesion (typically for $\mathrm{AE}$ ).

Both $\mathrm{CE}$ and $\mathrm{AE}$ are tumor-like diseases, most often located in the liver and also lungs for CE; dissemination may occur in any other organ/tissue. Echinococcosis may remain asymptomatic for a long period of time and spontaneous death of the metacestode occurs in many patients. Diagnosis relies on imaging, and incidental finding of an echinococcal lesion, especially in the liver, is not rare. Ultrasound (US) examination is the basis for diagnosis in patients with liver-related signs and symptoms and for mass screening.

For CE, drug treatment includes 3-6 month albendazole for small cysts or, at the opposite of the spectrum, longterm albendazole ( $>6$ months) for disseminated nonoperable CE. However, surgery remains the treatment of choice for most cysts. For AE, albendazole is the basis for care management in all patients, for a minimum of 2 years after radical surgical resection of the liver lesions; it must be administered for life, at least for decades, in all other cases; biliary complications and bacterial superinfection are treated by percutaneous or perendoscopic drainage and stenting.

Infection of humans occurs through ingestion of
Echinococcus eggs, excreted in the feces of definitive hosts. E. granulosus sensu lato is usually maintained by the domestic cycle (dog/domestic ungulates) and represents a persistent zoonosis in rural livestock-raising areas where humans cohabit with dogs fed on raw livestock offal in which the cysts are present. A cycle in wild animals allows E. multilocularis to occur in nature. It includes mostly voles of a number of different species and additionally lagormophs such as pikas in some areas, as intermediate hosts. Foxes, wolves and dogs are definitive hosts, and less commonly other carnivores. Environmental factors play a critical role in E. multilocularis infection in wild animals, resulting in a heterogeneous geographical distribution of the parasite and possibly influencing contamination of water. In many countries, dog and fox urbanization has considerably increased the human population at risk. Various types of association of CE and AE with water sources of the communities have been reported. Studies on the presence of infective eggs in the environment (including soil and plants/fruit/vegetables), using molecular tools, are just at their beginning. There are currently no published data on the presence of Echinococcus spp. eggs in sewage, sludge, surface waters, ground water, drinking water, soil or irrigation water. Echinococcus spp. eggs shed with carnivore feces are destroyed by heat (including water boiling) and desiccation but are very resistant to low temperature (until $-70^{\circ} \mathrm{C}$ ) and to all chemicals used for disinfection; they may be released into and are well preserved in water; they may also be dispersed in the soil through spreading of sludge from water treatment plants. Systematic studies on how various modalities of sewage treatment and sanitation may contribute to or conversely avoid human infection are needed.

\subsection{Epidemiology of the Disease and Pathogen(s)}

\subsection{Global Burden of Disease}

Echinococcus spp. are cestodes (tapeworms) and the species which cause disease are. E. granulosus, the agent of cystic echinococcosis (CE); E. multilocularis, the agent of alveolar ecUhinococcosis (AE); E. oligarthrus, the agent of a very rare form of CE in South America; and finally $E$. vogeli, the agent of polycystic echinococcosis (PE),

Dogs and other canine species (foxes) when infected spread the disease to people due to exposure to canine excreta.

\subsubsection{Global distribution}

\subsubsection{Cystic echinococcosis (CE)}

CE is a parasitic zoonosis reported in all continents with the exception of Antarctica, and very few islands are free from the infection (Eckert et al., 2001d; Eckert and Deplazes, 2004). Figure 1A shows the global distribution of Echinococcus granulosus sensu lato in the world, i.e. presence of one or another species of the cestode irrespective of their pathogenic potential to humans. 
Unfortunately, precise data are missing for a number of countries, especially in Africa, Russia and Central Asia; in addition, regarding cases in humans, data provided by governmental authorities or scientific studies rarely make the distinction between 'autochthonous cases', due to the presence of the parasite in the country, and 'imported cases', due to the migration of populations from highly endemic areas to less endemic areas: this is especially the case for Europe. An accurate picture of the situation is thus extremely difficult to obtain. The most comprehensive and exhaustive review of the global distribution of CE in humans and E. granulosus s.l. infection in animals was recently published by Deplazes et al.; all details and maps are available in that review (Deplazes et al., 2017). CE is especially prevalent in regions where sheep and livestock are raised, including especially those where nomadism, transhumance and family slaughtering are common (MacPherson, 2001). The 'domestic' (also called 'synanthropic') cycle with high zoonotic potential is maintained between the domestic dog and livestock in pastoral communities. The exact identification of endemic areas and quantification of CE burden is difficult due to lack of data and significant underreporting of both human and animal cases. Moreover, hospital records may not reflect accurately the real prevalence of infection, as CE is often asymptomatic and affects communities with limited access to health facilities (Yang et al., 2006). Prevalence and incidence of human infection vary greatly between areas and reports, reaching peaks of $12 \%$ prevalence and annual incidence of 80/100,000 in certain communities of Xinjiang or Qinghai (China) where up to $99 \%$ of sheep are infected (Craig et al., 2007). The most endemic regions are South America, the Mediterranean, Central-Eastern Europe, especially Romania and Bulgaria, north and east Africa, the Middle East, central Asia, all countries of the Indian subcontinent, western and north-eastern China, and Australia (Craig et al., 2007; Eckert et al., 2001d; Torgerson, 2013). Western China (Xinjiang, Qinghai, Gansu, Ningxia, Inner Mongolia, Sichuan, Tibet) certainly represents the region in the world where most of CE cases are diagnosed (Craig et al., 2007). In endemic countries and because of the accelerated urbanization of rural population, CE can also occur in urban centers where transmission occurs in unlicensed and unsupervised abattoirs (Reyes et al., 2012). In North-Western Europe and North America, CE is usually diagnosed in patients coming from endemic areas (immigrants, travelers) although a few autochthonous cases may be described (Eckert et al., 2001d).

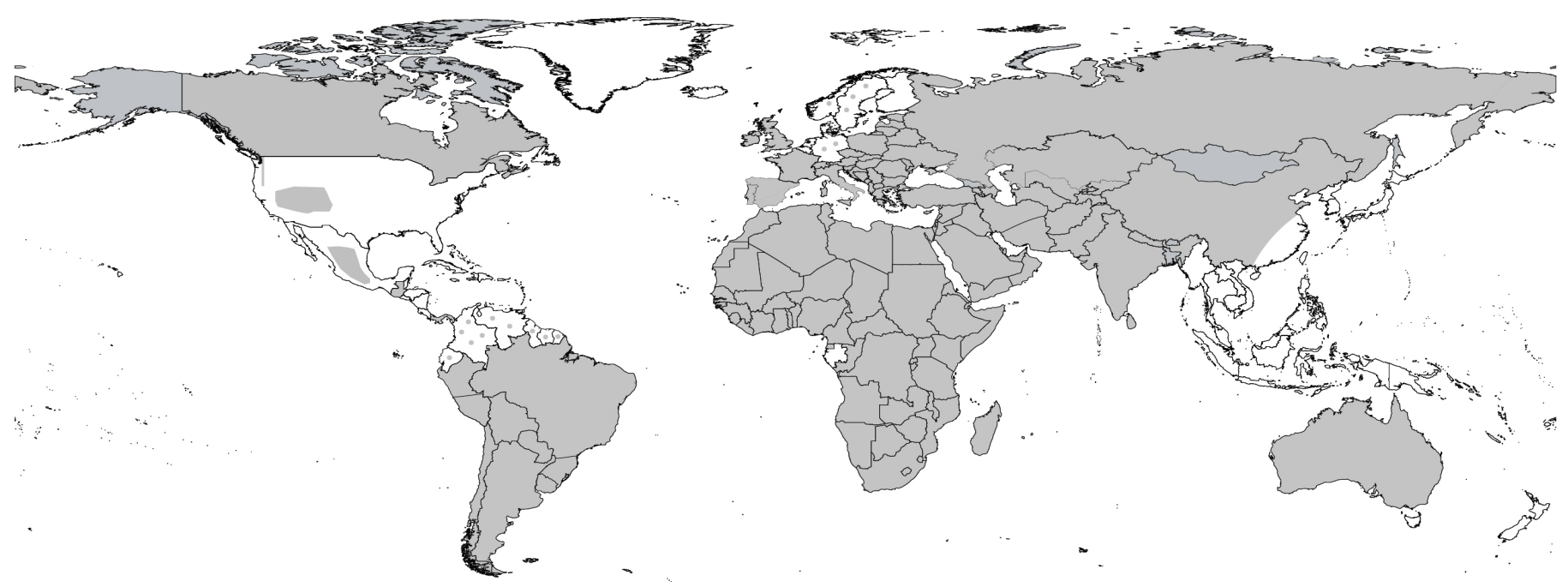

Figure 1A. Global distribution of Echinococcus granulosus sensu lato, irrespective of the species and of their pathogenic potential to humans. Detailed information and original maps may be found in the review by Deplazes et al., 2017. 


\subsubsection{Alveolar echinococcosis (AE)}

$\mathrm{AE}$ is a rare parasitic zoonosis only observed in the northern hemisphere. AE cases in humans are in geographical areas where E. multilocularis sylvatic life cycle can occur (Figure 1B)(Eckert et al., 2001c; Vuitton et al., 2015; Vuitton et al.,2003). The current status of the global distribution of $\mathrm{AE}$ in the world is also given in details in the review by Deplazes et al. (Deplazes et al., 2017). AE is a rare disease in most endemic regions where the cycle is maintained in the wild life only $(<10 / 100,000$ in regions with $70 \%$ of foxes infected and in most of the areas in Central Europe under 1 case per 100 000) (Piarroux et al., 2013; Vuitton et al., 2015), due to both the rare encounter of humans with infected fox feces and by their natural resistance as an intermediate host (Vuitton et al., 2003; Vuitton and Gottstein, 2010).

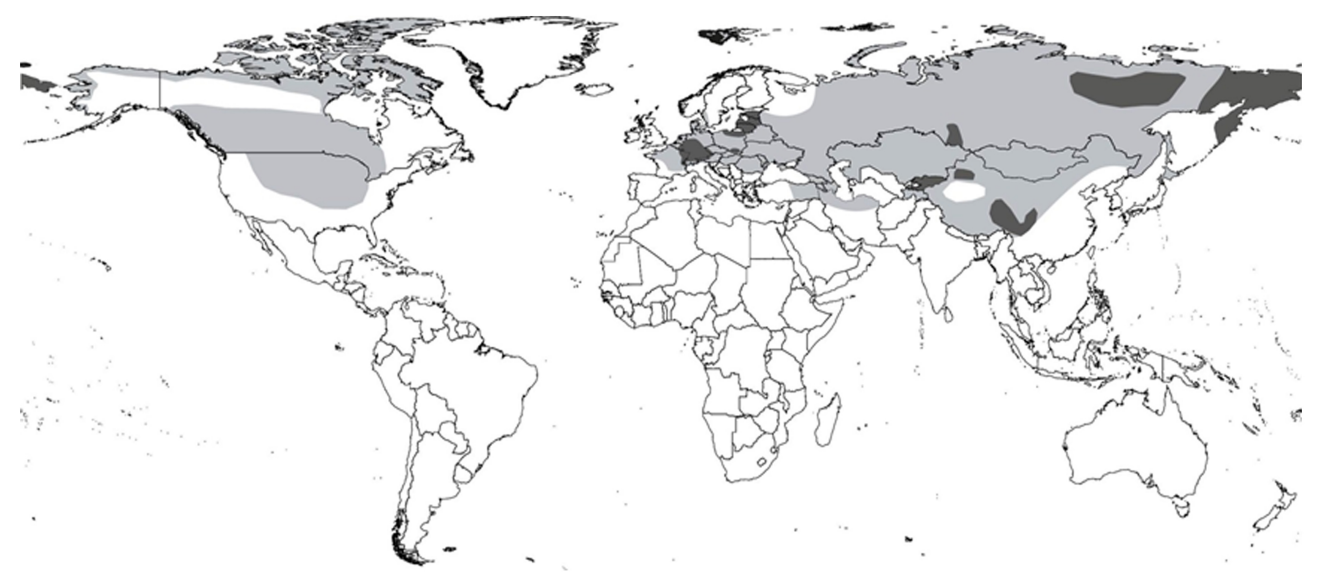

Figure 1 B. Approximate geographic distribution of Echinococcus multilocularis in the world. Grey areas: areas where E. multilocularis presence has been reported; dark grey areas: known hostpots of human AE (here, hotspots are defined as areas with human AE prevalence more than 10-100 times higher than the regional surroundings, see Said-Ali et al.(Said-Ali et al., 2013); hence, average prevalence greatly varies from one hotspot to the other); white areas: areas where the parasite has not been reported or cannot be present (e.g. dry desert). Hotspots with question marks are presumed by Eckert et al., 2001d, but no update has been available for more than 50 years. After (Combes et al., 2012; Davidson et al., 2012; Eckert et al., 2001d; Giraudoux et al., 2013a; Giraudoux et al., 2013b; Konyaev et al., 2012; Massolo et al., 2014; Vuitton et al., 2015; Vuitton et al., 2003).

It is far more frequent where the cycle involves dogs such as in endemic areas of western China, which is now considered the region with the highest number of human AE (Craig et al., 1992; ; Ito et al., 2003; Vuitton et al., 2003 ), up to 100 times higher than that in the endemic areas of Europe. In China, Turkey, and Central Asia, CE and AE coexist in some communities and sometimes in the same patient or in the same definitive host (Wen et al., 2006; Wen et al.,1992; Xiao et al., 2006; Yang et al., 2006a; Y. Zhang et al., 2006). 
After one and a half century when endemic areas with human AE cases were restricted to Germany, Switzerland, Austria and France, in the last two decades, endemic areas have been recognized in nearly all Europe, with foxes infected with $E$. multilocularis being reported in all the countries, except the UK, Ireland, Spain, Portugal, Malta and Finland (Romig, 2009; Vuitton et al., 2015). Baltic States now definitely appear to be major endemic areas for the disease in humans (Gottstein et al., 2015; Marcinkute et al., 2015). Only 4 EU countries which apply specific regulations to enter a pet are declared free of the disease; these are the UK, Malta, Finland and Ireland. Although no specific investigations have ever been done in Spain and Portugal, no human cases of AE have ever been found in these countries. Mainland Norway seems also to be $E$. multilocularis-free, but the parasite is present in the northern Norwegian Svalbard islands (Knapp et al., 2012). In Japan and Europe, fox urbanization is posing new issues for the prevention of AE (Deplazes et al., 2004). An active parasite cycle has long been recognized in Alaska, together with AE cases in humans (Wilson et al., 1995); infection of wild animals by $E$. multilocularis has been well identified in north-central USA States (Storandt et al., 2002)and more recently in Canada, including in cities where coyotes were found infected by a European-type strain (Catalano et al., 2012; Massolo et al., 2014). Human cases were extremely rare until recently when $\mathrm{AE}$ cases were found in a primate in a zoo of British Columbia, Canada (Christiansen et al., 2015), and in humans in Alberta, Canada, of them one case in an immunosuppressed patient (Massolo et al., 2014) (Massolo, personal communication).

\subsubsection{Symptomatology}

\subsubsection{Cystic echinococcosis (CE)}

CE presents usually as a cyst in the liver or in the lung, which may remain clinically silent for a long time (several months to several years) and is often discovered incidentally during routine abdominal ultrasound (US) examination or chest X-ray. All other anatomical locations are possible but rarer, as shown in a large collection of cases in Australia where the most frequent locations of 1,802 cysts were liver (63\%), lung (25\%), muscles, (5\%), bones (3\%), kidney (2\%); spleen, brain (1\%), and heart, breast, prostate, parotid and pancreas (<1\%) (Pawlowski et al., 2001; Torgerson et al., 2011). Similar figures are given from more recent series of cases. Clinical symptoms are usually absent until the cyst has reached $10 \mathrm{~cm}$ in diameter; a cyst is rarely palpable until it has reached $15-20 \mathrm{~cm}$. Systematic mass screening using US examination of the liver may find asymptomatic cysts; this mode of CE diagnosis is more and more frequently used in countries where governmental actions are undertaken, such as China, as well as Argentina, Uruguay, or Peru in South America. Such mass screening campaigns, also launched by nongovernmental organizations or research teams, have shown that liver cysts had a very slow and limited growth: in more than half of the cysts there were no modifications in cyst size during the 10-12-year period of observation, in one third, growth was slight $(<3 \mathrm{~cm})$ and in only one case, $(7 \%)$ the cyst grew by $4 \mathrm{~cm}$. Mean cyst growth in cases with a prolonged follow-up was $0.7 \mathrm{~cm}$ (Frider et al., 1999; Wang et al., 2006).

The WHO-Informal Working Group on Echinococcosis (IWGE) has promoted a unified classification (Figure 2), which is currently used as a standard to compare data from mass screenings and results of therapeutic interventions (WHO-Informal Working Group on Echinococcosis, 2003). When the cysts become symptomatic, the most common signs and symptoms at presentation are right upper quadrant discomfort; urticaria; episodes of itching; and/or right upper quadrant palpable mass. Physical examination of the liver may be normal or may disclose an enlarged and regular liver. If the cyst is located in the anterior liver, a round, painless tumour can be palpated. A complication is most often at the origin of liver CE diagnosis. Signs and symptoms of complications are mainly jaundice by compression of or rupture into the bile ducts. Compression of portal or hepatic veins or of inferior vena cava is uncommon. 


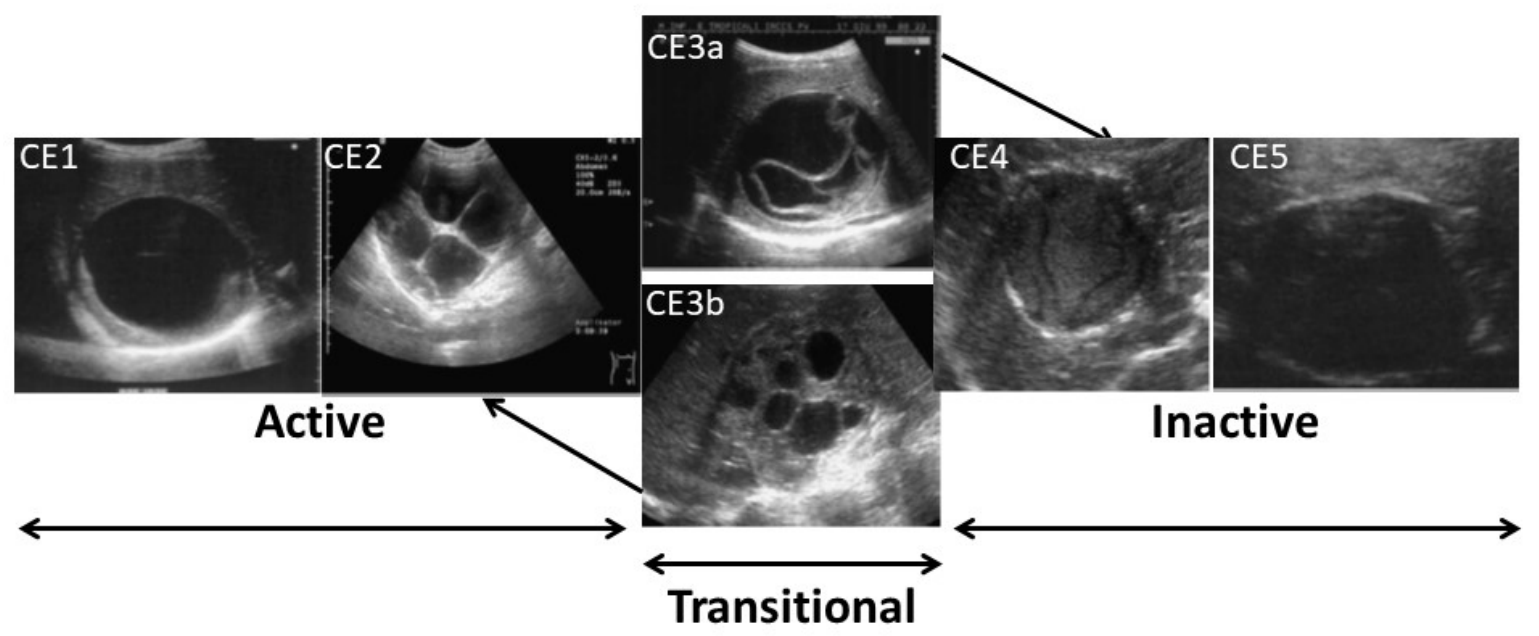

Figure 2. WHO-Informal Working Group on Echinococcosis classification of CE cases, based on ultrasound images [after WHO-IWGE (WHO Informal Working Group, 2003) and Junghanss et al., (Junghanss et al., 2008) with modifications]. CE1: Unilocular unechoic cystic lesion with double line sign; CE2: Multiseptated, "rosette-like" cyst; CE3a: Cyst with detached membranes (water-lily-sign); CE3b: Cyst with daughter cysts in solid matrix; CE4: Cyst with heterogenous hypoechoic/hyperechoic contents, no daughter cysts; CE5: Solid lesion with calcified wall. The 'CL' cyst, i.e. simple cyst without any specific character of CE, is not represented in this figure but justifies a 'watch and wait' attitude, according to the recommendations of the WHO-IWGE.

Allergic reactions such as anaphylactic shock, eosinophilia, urticaria, and/or acute abdominal pain may be observed in case of cyst rupture in the peritoneal cavity, spontaneous or provoked by any abdominal trauma (especially during sport practice). Depending on the series/country/setting, at diagnosis, 30 to 40 per cent of hepatic cysts diagnosed in hospital settings have ruptured or become infected (Pawlowski et al., 2001). In a recent study in India, $26 \%$ of liver cysts were either ruptured or infected when referred to surgeons (Malik et al., 2010). Cysts located near the diaphragm can erode it and extend into the pleural and pericardial cavities, the lung, or rupture into the bronchi. Cysts close to the peritoneal cavity may rupture into the peritoneum or into the duodenum, stomach, colon, or right renal pelvis. These ruptures may lead to extra-hepatic CE by the dissemination of E. granulosus germinal layer fragments and of protoscoleces. They also favour the development of 'daughter cysts' in or out the initial cyst. More commonly, the rupture of cyst occurs into bile ducts, and is revealed by jaundice, cholangitis, or biliary pain. Some ruptures into bile ducts may be clinically silent, and are thus only disclosed during an operation. Among lung cysts referred to surgeons, complicated cysts are also frequent, including lung abscess, pleuritis, pneumonitis and fibrosis (Ghoshal et al., 2012).
Cough, hiccups, and chest pain are the main symptoms of lung cysts when there are not diagnosed by chance on a chest X-ray. Cyst rupture is also a frequent opportunity for diagnosing lung cysts: rupture in the bronchi may be followed by elimination of cyst fluid and materials (membranes, protoscoleces) by cough (Ghoshal et al., 2012).

\subsubsection{Alveolar echinococcosis (AE)}

$\mathrm{AE}$ presents as a pseudo-tumor, located in the liver in more than $95 \%$ of cases in humans. In endemic areas of China, Russia or Central Asia, except in those regions where a systematic mass screening of the population is implemented, $\mathrm{AE}$ is frequently recognized at an advanced stage and misdiagnosed as liver cancer or cirrhosis (Ayifuhan et al., 2012). Jaundice is the most frequent presenting symptom, in half of cases. It is either progressive jaundice related to hilum involvement, associated with pruritus, or intermittent jaundice with pain and fever related to bacterial infection of the obstructed bile ducts (Figure 3). Hepatomegaly, generally massive, is also a possible revealing symptom in a quarter of cases. This was also the situation before the 1980s in the European endemic area (Bresson-Hadni et al., 2000; Kern et al., 2003). 

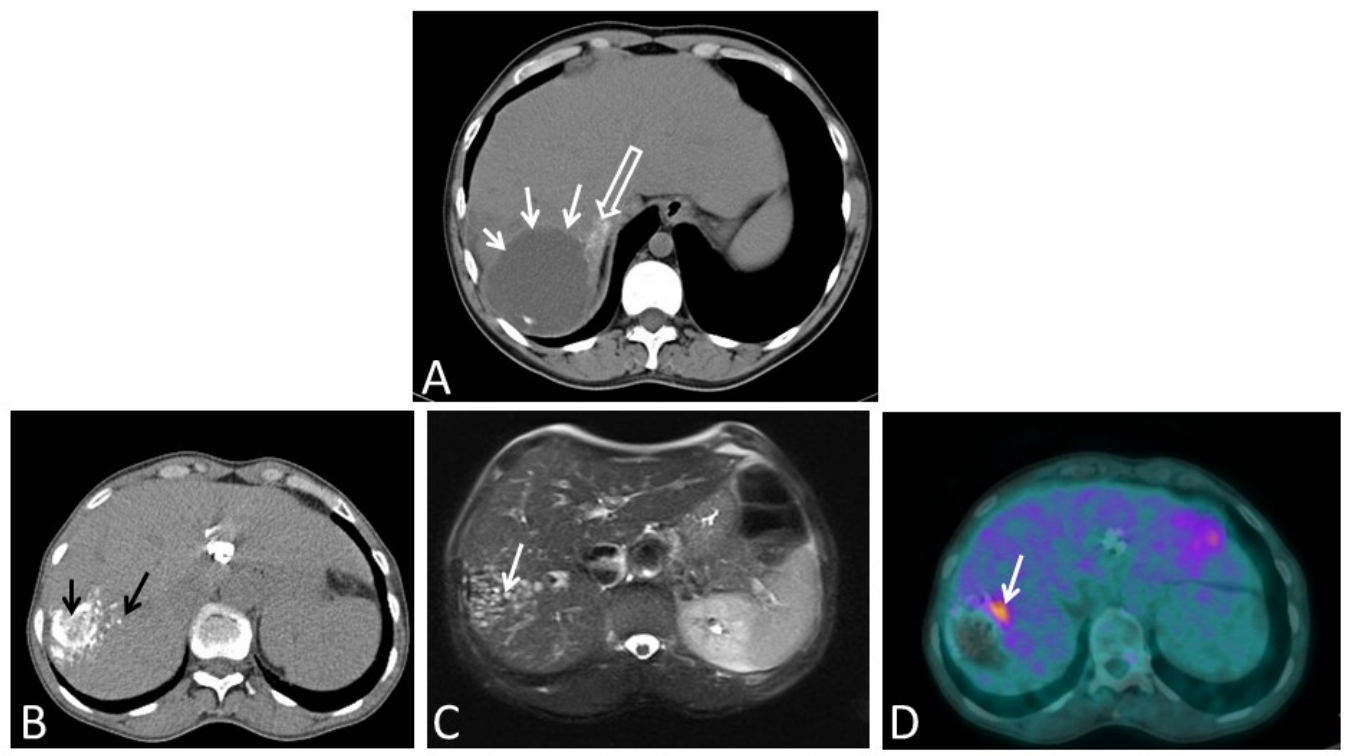

Figure 3. Typical images of alveolar echinococcosis (AE) of the liver.

A. Computed Tomography (CT) image of and advanced case of AE. The central 'pseudo-cystic' hypodense area (contour indicated by 3 full arrows) is not a cyst as it may be observed in CE but corresponds to a necrotic cavity inside the AE lesion. Typical hyperdense calcifications may be seen at the border of the lesion (empty arrow).

B, C, D. AE lesion in the right lobe of the liver of the same patient: different components of the lesion may be shown by different imaging exams. B. CT image which shows the calcifications both grouped and scattered inside the lesion (black arrows). C. Magnetic resonance imaging (MRI) T2 weighted image which shows the microcysts arranged in a "honeycomb" of "bunch of grapes" manner, characteristic of an AE lesion. D. Positron Emission Tomography (PET, combined with CT scanning): positive 18F-fluoro-deoxy-glucose (FDG) uptake by the active immune response of the host at the periphery of the lesion (white arrow). The development of calcifications (best shown by CT scanning) coexists with the presence of micro-cysts (best shown on MRI T2 weighted images) and positive PET (best shown on images taken 3 hours after FDG Injection) which both demonstrate the viability of the metacestode in the liver lesion.

Images provided by Eric Delabrousse and Amel Azizi, department of radiology; WHO-Collaborating Centre on Prevention and Treatment of Human Echinococcosis, University Hospital, Besançon, France.

During the past 30 years in Europe and Japan, changes in the revealing symptoms have occurred, because of disclosure of less severe and asymptomatic cases, mostly due to the wide use of US exams for a variety of symptoms/diseases. Less than $25 \%$ of cases are revealed by jaundice; and hepatomegaly is observed in only $15 \%$ of the cases. Discomfort in the right upper quadrant is a revealing symptom in about $30 \%$ of cases. The contrast between a hepatomegaly mimicking a liver carcinoma or advanced cirrhosis and a good clinical status raises the suspicion of $\mathrm{AE}$ in endemic areas.
Erratic clinical signs and symptoms generally due to metastases or extra-hepatic location of the parasite may also be observed at presentation (Bresson-Hadni et al., 2007; Piarroux et al., 2011). The WHO-Informal Working Group on Echinococcosis (IWGE) has promoted a unified staging of $\mathrm{AE}$, the PNM system designed on the model of the TNM classification of cancers, which helps clinicians to choose the appropriate treatment and the clinical teams to evaluate their results comparatively (Kern et al., 2006) (Table 1). Cases are more frequently asymptomatic when they are disclosed in immune suppressed patients. This may occur when organ location/dissemination of cancer, lymphoma or leukemia is looked for during patient's followup, or when pre-treatment evaluation is performed for systemic inflammatory/autoimmune diseases, or during the follow-up of patients after organ transplantation (Chauchet et al., 2014; Kern et al., 2011). 
Table 1. PNM classification and staging of alveolar echinococcosis, according to WHO-Informal Working Group on Echinococcosis; according to Kern et al., 2006.

\section{PNM classification of AE cases (at presentation)}

\section{P Hepatic localisation of the Parasite}

P X Primary tumor cannot be assessed

P 0 No detectable tumor in the liver

P 1 Peripheral lesions without proximal vascular and/or biliary involvement

P 2 Central lesions with proximal vascular and/or biliary involvement of one lobe

P 3 Central lesions with hilum vascular or biliary involvement of both lobes and/ or with involvement of two hepatic veins

P 4 Any liver lesion with extension along the vessels and the biliary tree

N Extra hepatic involvement of neighboring organs [diaphragm, lung, pleura, pericardium, heart, gastric and duodenal wall, adrenal glands, peritoneum, retroperitoneum, parietal wall (muscles, skin, bone), pancreas, regional lymph nodes, liver ligaments, kidney]

N X Not able to evaluate

N 0 No regional involvement

N 1 Regional involvement of contiguous organs or tissues

M The absence or presence of distant Metastasis [lung, distant lymph nodes, spleen, CNS, orbital, bone, skin, muscle, kidney, distant peritoneum and retroperitoneum]

M X Not completely evaluated

M 0 No metastasis

M 1 Metastasis

a For classification, the plane projecting between the bed of the gall bladder and the inferior vena cava divides the liver in two lobes; b Vessels mean inferior vena cava, portal vein and arteries; c Chest X-ray and cerebral CT negative.

The most frequent complications of $\mathrm{AE}$ are bacterial or fungal infection of the bile ducts and/or of the central necrotic area of lesions, frequent in advanced cases, with sepsis and septic shock (Bresson-Hadni et al., 2007; Kern, 2010). Loco-regional extension or a spread of parasitic tissue via the vessels leading to distant metastases may cause a variety of symptoms ranging from dyspnea and biletinged sputum to seizures and stroke as well as skin nodules or bone pain or fractures. Unlike what happens with $\mathrm{CE}$, anaphylactic reactions as revealing symptoms are extremely rare; the occurrence of such symptoms is always associated with systemic dissemination of parasitic fragments through the vessels. Bleeding from esophagogastric varices related to portal hypertension, secondary to biliary cirrhosis or to chronic thrombosis of the hepatic or portal veins have become rare because of a more systematic prevention and treatment of such varices in European and Japanese centers; they remain frequent in China and other endemic areas (Ayifuhan et al., 2012; Bresson-Hadni et al., 2006).

\subsubsection{Morbidity and mortality ratios}

\subsubsection{Cystic echinococcosis (CE)}

CE is a chronic disease and usually considered benign since in most cases a simple surgical operation may remove the cyst totally. However, surgery is an invasive and costly procedure which is not always available with the best chance of success and safety in many of the highly endemic countries. Drug therapy is not very effective; compared to other parasitic diseases which benefit from short-term treatments, anti-parasitic treatment has to be taken for months and strict follow-up is mandatory. Studies on the public health burden by echinococcosis have only begun in the 21st century (Carabin et al., 2005; Carabin et al., 2004).

The WHO has included CE in its strategic roadmap for 2020, and, according to the 2nd WHO report on neglected tropical diseases, the efforts are underway to address the burden and impact of CE in select countries (Foodborne Diseases Epidemiology Reference Group, 2015; World Health Organisation, 2013); specific programs have also 
been launched in highly endemic emerging countries, such as China (The Central People's Government of the People's Republic of China, 2014). Mortality and fatality rates are difficult to estimate and vary greatly depending on the prevalence of the disease and health facilities in a given area, as well as on cyst location and severity of disease at presentation. On average the reported figures show a mortality rate of $0.2 / 100,000$ inhabitants and 2.2 fatality rate/100 patients with the disease (Pawlowski et al., 2001). However, absence of long term follow-up significantly underestimates recurrence rate (2-25\%) and long-term complications after surgery.

For CE, the first global estimate of the non-monetary burden of CE was conducted in 2006 and used the DALY to evaluate losses associated with human cases (Budke et al., 2006). Without adjusting for underreporting, an estimated 285,400 DALYs were lost due to CE. If underreporting is taken into account, estimation reached 1,010,000 DALYs, a higher figure than that given for Dengue or Chagas disease (Budke et al., 2006; Craig et al., 2007). The 2010 and 2013 Global Burden of Diseases (GBD) studies included DALY estimates for 'echinococcosis' and CE, respectively (Murray et al., 2015, 2012). However, methodological decisions make interpretation of the $2010 \mathrm{GBD}$ values problematic in that the study attempted to combine CE and AE into a single estimate, which is hardly acceptable (Hotez et al., 2014; Murray et al., 2012). The 2013 GBD Study focused solely on CE (Murray et al., 2015). However, data gaps remain a problem. In parallel to the 2010 GBD Study, the World Health Organization's Foodborne Disease Burden Epidemiology Reference Group (WHO-FERG) published global CE burden estimates for the year 2010 (Foodborne Diseases Epidemiology Reference Group, 2015; Havelaar et al., 2015; Torgerson et al., 2015). Relatively few investigator-driven studies have been conducted to estimate the non-monetary burden of CE in specific regions using the DALY. The first study was performed in 2004 in a highly endemic region of the Tibetan Plateau in Sichuan province of China; it evaluated at about 18,000 DALYs the burden of this chronic disease on populations who could not readily obtain medical treatment (Budke et al., 2004). Other studies have since been conducted in diverse geographic locations, including Peru, Sardinia, Nepal, and Xinjiang, China (Devleesschauwer et al., 2014; Mastrandrea et al., 2012; Moro et al., 2011; Wang et al., 2012).

Annual economic losses due to diagnosis and treatment costs in humans have been estimated at over 763 million US \\$, while global annual livestock-associated losses were calculated at over 2,190 million US $\backslash \$$ (Budke et al., 2006). The lack of a standardized methodology, however, makes comparisons difficult since the categories of costs included may vary greatly between studies. While a few studies have estimated only livestock-associated costs, most studies with a livestock component also estimate monetary losses associated with human CE ((Ahmadi and Meshkehkar, 2011; Benner et al., 2010; Budke et al., 2005b; Fasihi Harandi et al., 2012; Majorowski et al., 2005; Moro et al., 2011; Sariözkan and Yalçin, 2009; Torgerson et al., 2001; Torgerson et al., 2000; Torgerson and Dowling, 2001; Venegas et al., 2014). But these studies which have now covered several countries with various levels of development and income and various health systems have all shown that CE can have a substantial impact on both the human and livestock sectors in endemic regions.

\subsubsection{Alveolar echinococcosis (AE)}

AE was considered as a fatal disease within 5 years after diagnosis in $80 \%$ of patients in Europe in the late 1970s (Bresson-Hadni et al., 2000). In Europe and Japan, between the 1980s and the 2000s, there has been constant progress in the overall prognosis of the disease and average survival of the patients has changed dramatically. Whereas a patient's life expectancy was reduced by 18-21 years if diagnosed in 1970, life expectancy is only shortened by about 3 years compared to the normal Swiss population in recently diagnosed patients (Torgerson et al., 2008). The reasons for this improved prognosis are multifactorial, including earlier diagnosis, the introduction of treatment with benzimidazoles at the beginning of the 1980s, better surgical techniques and multidisciplinary care management in expert centers. However, among patients of the same cohort who could not benefit from radical operation, late biliary complications (i.e. occurring 3 years or more after diagnosis) were associated with poor prognosis (Frei et al., 2014). In France, if it is estimated one year after diagnosis, life expectancy of AE patients is similar to that of their non-AE fellow citizens (Piarroux et al., 2011). However, the observed survival of 347 patients $(2,742$ person-years) was lower than the expected survival in the general population matched for sex, age, and calendar-year ( $p<0.001$ ); in fact, the baseline excess mortality hazard decreased steeply during the first 2 years and remained close to that of the general population until 5 years of follow-up (Piarroux et al., 2011).

Poor prognosis is associated with older age and invasion of the liver hilum, responsible for biliary complications; conversely, medical treatment with benzimidazoles (with or without surgery) is associated with a better survival (Piarroux et al., 2011). In different recent $\mathrm{BMZ}$ cohort studies the 10 and 15-year survival rate was $80 \%$ to $83 \%$ and $53 \%$ to $80 \%$, respectively compared 0 to $25 \%$ at ten years in the pre-BMZ area (Ammann, 2000; Ammann et al., 1999; Bresson-Hadni et al., 2000; Caoduro et al., 2013; Kadry et al., 2005; Reuter et al., 2000; Wilson et al., 1992)

$\mathrm{AE}$ is still a lethal disease short term after diagnosis in those symptomatic patients who live in most of the endemic areas, such as central Asia or China: retrospective series of $\mathrm{AE}$ patients in western China account for advanced cases, and in a recent surgical series mortality (25\%) was mostly observed in patients having received palliative surgery (Ayifuhan et al., 2012). In Europe, although survival has increased a lot, impairment of quality of life due to continuous treatment administration and occurrence of complications with iterative interventions still make the disease a major burden individually and at the society level.

The global burden of AE, at the world level, is lower than that of $\mathrm{CE}$, mostly because of the far lower number of cases. Annual loss due to AE has been estimated at 666,434 DALYs (CIs 331,000-1.3 million) (Torgerson et al., 2010). 
However, $\mathrm{AE}$ is a very severe disease similar to liver cancer and requires complex and expensive treatments, often lifelong. This considerably increases the cost of the disease, evaluated in Europe to an average of 108,762€ per patient (Torgerson et al., 2008). In the first study on AE using the DALYs, in remote transhumant communities of Sichuan, China, the DALYs lost due to AE amounted 33,000, so twice that of CE for a slightly lower prevalence of the disease (Budke et al., 2004). Due to the prevalently wild cycle of $E$. multilocularis, there is no special veterinary or economic impact from the infection of the intermediate hosts. However, AE may be recognized in a number of domestic or zoo animals, such as horses, pigs, boars, which generally exhibit degenerated lesions, as well as chinchillas, monkeys, or even dogs which thus appear to also serve occasionally as intermediate hosts (Böttcher et al., 2013; Deplazes and Eckert, 2001a; Scharf et al., 2004; Ueno et al., 2012) AE in zoo animals mostly affects primates (Christiansen et al., 2015; Deplazes and Eckert, 2001a; Rehmann et al., 2005), including animals that belong to endangered species, such as lemurs (Umhang et al., 2016); albeit anecdotal, this may participate in the monetary as well as non-monetary losses due to $\mathrm{AE}$.

\subsection{Taxonomic Classification of the Agent (s)}

\subsubsection{Taxonomic position}

Echinococcus spp. are cestodes (tapeworms) of the family Taeniidae, with a predator-prey life cycle and a complex biology (Deplazes and Eckert, 2001a; Eckert and Deplazes, 2004). Until the end of the 20th century, 4 species were identified in the genus Echinococcus: $E$. granulosus, the agent of cystic echinococcosis (CE); $E$. multilocularis, the agent of alveolar echinococcosis (AE); E. oligarthrus, the agent of a very rare form of $\mathrm{CE}$ in South America; and $E$. vogeli, the agent of polycystic echinococcosis (PE), also in South America. Progress in genetic characterization of species has made the situation more complex. It is currently internationally accepted by taxonomists that a new species close to $E$. multilocularis is present in western China, E. shiquicus, never recognized to infect humans (Xiao et al., 2005), and that several species may be identified within E. granulosus sensu lato, namely E. granulosus sensu stricto (ex-sheep strain), E. felidis (exlion strain) and E. equinus (ex-horse strain, both species never recognized to infect humans), E. ortleppi (ex-cattle strain), and E. canadensis (ex-camel, pig and cervid strains) (Alvarez Rojas et al., 2014; Knapp et al., 2015; Romig et al., 2015) Sister species relationships were confirmed between E. ortleppi and E. canadensis, and between E. multilocularis and E. shiquicus. Nuclear and mitochondrial targets most often used for the genotyping of $E$. multilocularis have shown a marked genetic homogeneity in this species; microsatellite sequences, such as the EmsB target (Bart et al., 2006), are able to discriminate isolates on a regional and sectorial level (Knapp et al., 2007), and to draw fine-tuned maps of the parasite variants occurring worldwide (Afonso et al., 2015; Knapp et al., 2010). 1.2.2 Physical description (morphology).

The adult worm is $2-7 \mathrm{~mm}$ long and resides in the small intestine of the definitive hosts (carnivores) (Deplazes and Eckert, 2001a; Thompson and McManus, 2001) (Figure 4). It is composed of a head (the scolex) with four suckers and a rostellum with a double ring of 25-50 hooklets and a body (the strobilus) composed of 2-6 segments (the proglottids). The proglottids mature progressively from the scolex end within one to one and a half month, and the last proglottid contains the genital organs which produce eggs (oncospheres). Each worm is hermaphrodite. 


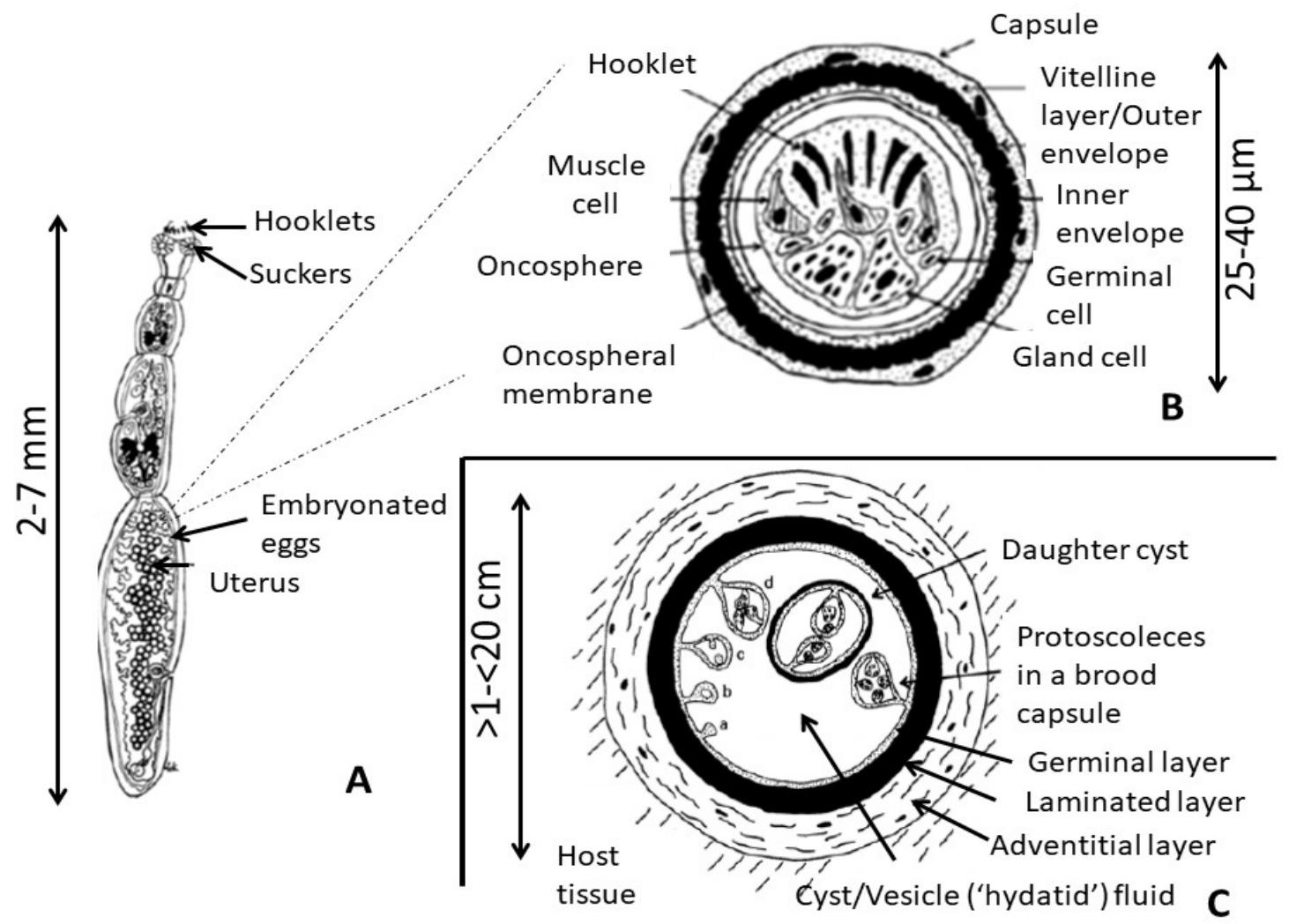

Figure 4. The key-stages of the development of Echinococcus spp. (after Thompson et al., 2001 (Thompson and McManus, 2001) with modifications):

A. The worm (4 to $7 \mathrm{~mm}$, for Echinococcus granulosus s.l.) is attached to the intestinal mucosa of definitive hosts (carnivores) by its suckers and hooklets; the gravid uterus in the last segment of the worm contains hundreds of embryonated eggs.

B. The egg $(25$ to $40 \mu \mathrm{m})$ contains the infectious oncosphere surrounded by a resistant envelope; thousands of such eggs are dispersed in the environment (grass, soil, water) after the expulsion of the worm's last segment with the feces of the carnivore host.

C. The metacestode (or 'larva', a few mms to $20 \mathrm{~cm}$ or more) settles and grows in the liver of an intermediate host (mostly ungulates for E. granulosus sensu lato, small mammals for E. multilocularis); its germinal layer produces brood capsules with protoscoleces, infectious to the definitive hosts but also able to generate a metacestode in an intermediated host; the germinal layer secretes the vesicle/cyst fluid (also called 'hydatid' fluid); it also secretes and is surrounded by the laminated layer. In E. granulosus sensu lato spp. (shown as an example), the host's cellular immune response is rapidly responsible for the development of a fibrous acellular adventitial layer.

The eggs are 25-30 $\mu \mathrm{m}$ in diameter, round/oval in shape, and totally similar to eggs of other taeniid worms of carnivores (Figure $4 \mathrm{~B}$ ); they consist of a striated envelope (the embryophore) which contains the embryo (also called 'hexacanth embryo', because of its shape) (Thompson and McManus, 2001). They are the only 'free stage' of Echinococcus spp. cestodes, dispersed in the environment with the feces of the definitive hosts. 
The larva (metacestode) develops in different organs of the intermediate hosts, mainly the liver and the lungs. The metacestode has a cystic development; the cysts are filled with transparent liquid ('hydatid fluid', or 'cyst fluid', or 'vesicle fluid'), and are composed of an inner layer represented by the viable larva (the germinal layer) and an outer cell-free layer (the acellular laminated layer) mainly composed of polysaccharides. CE is characterized by unilocular macro-cysts (1 to $20 \mathrm{~cm}$ in diameter or more) surrounded by a fibrous shell (Figure $4 \mathrm{C}$ ), AE by an aggregation of micro-cysts (a few $\mathrm{mm}$ to $2 \mathrm{~cm}$ in diameter) surrounded by a mix of immune cells, fibrosis and necrosis, and PE by an aggregation of cysts of intermediate size (a few $\mathrm{cm}$ in diameter). Fertility, i.e. development of precursors of the scoleces, the protoscoleces (PSC), from the germinal layer and their release in the cyst fluid, depends on the host-parasite strain combination. The metacestode of E. granulosus (also commonly called 'hydatid cyst' in the past) is a fluid-filled bladder that grows centrifugally and can survive decades in the intermediate host. The growth rate of cysts varies greatly between host species (Thompson and McManus, 2001). AE lesions consist of a mass of small vesicles that grow by infiltration invading also tissues close to the liver or disseminating in larval microthrombi via the bloodstream. Advanced lesions (after years of progression) often contain a central necrotic cavity (pseudo-cyst) and acellular fibrosis(Vuitton et al., 2006).

\subsection{Transmission}

\subsubsection{Lifecycle and routes of transmission (Figure 5)}

Dogs (for all species), various species of foxes (mostly for E. multilocularis), and other canids such as wolves, coyotes, dingoes, jackals, or raccoon dogs, and also felids, including wild felids in Africa (for E. felidis) and domestic cats in Europe (for E. multilocularis) are the definitive hosts of Echinococcus spp (Eckert et al., 2001a). The respective role of one species or another, and within a single species of the various individuals, in the transmission of Echinococcus spp. eggs, depends on the geographic and cultural characteristics of the endemic area as well as the age, gender or behavior of the definitive animal host (Otero-Abad and Torgerson, 2013). The bush dog, Speothos venaticus, appears to be the only natural definitive host of E. vogeli, but dogs may also serve as definitive hosts (do Carmo Pereira Soares et al., 2014). Carnivores get infected by preying on the intermediate hosts whose viscera contain fertile metacestodes with infectious protoscoleces. The protoscolex represents an invaginated form of the adult worm; protoscoleces evaginate in the intestine of the definitive host under the influence of gastric proteolytic enzymes and of bile acids in the duodenum, and get attached to the gut mucosa with their suckers and hooklets. A given carnivore may be infected by less than ten worms to more than ten thousands of worms, and this depends both of its species and of the initial infection by protoscoleces (Eckert et al., 2001a; Thompson et al., 2006).

They mature towards fertility, with a prepatent period (before egg expulsion) of 4-7 weeks. The last proglottid of each worm is released every 1-2 weeks. Proglottids and the eggs they contain are dispersed in the environment with the feces of the definitive hosts, and the eggs are released. The longevity of the worms in the dog may be from 6 months to 2 years (Gemmell et al., 1986; Thompson and Kumaratilake, 1985). Re-infection is possible, although the parasite load and egg production become lower in reinfected definitive hosts (Al-Sabi et al., 2008; Eckert et al., 2001a). Intermediate hosts get infected via the fecal-oral route by ingestion of eggs, present in soil, water, grass, vegetables, fruit...or by direct contact with the fur of carnivores where eggs may be deposed by licking. After ingestion by intermediate hosts, eggs hatch in the duodenum, and the free hexacanth embryo penetrates the gut wall.

A 'domestic' cycle for E. granulosus s.l. has long been opposed to a 'wild life' cycle for E. multilocularis; however, species identifications of Echinococcus spp. by molecular biology techniques have well shown that wild animals such as wolves could be definitive hosts for E. granulosus s.l., 
including in Europe (Gori et al., 2015; Guerra et al., 2013) as well as dogs could be so for E. multilocularis, especially in China and central Asia (Budke et al., 2005a; Vaniscotte et al., 2011; Vuitton et al., 2003).

\subsubsection{Intermediate hosts and reservoirs}

Intermediate hosts of E. granulosus sensu lato are ruminants, mostly sheep, cattle and camels, as well as horses, pigs, and other mammals, such as moose or kangaroos (Eckert et al., 2001a; Torgerson et al., 2011). Intermediate hosts of E. multilocularis are usually wild small mammals of a wide variety of species and of susceptibility to the cestode, they are mostly rodents, especially voles (more than 40 species have been described to be potential hosts), and also the lagomorph Ochotona curzoniae and other lagomorphs such as hares, on the Tibetan plateau of China (Vuitton et al., 2003) and less commonly other aberrant intermediate host including dogs and cats which may be intermediate hosts accidentally (Deplazes and Eckert, 2001b). Intermediate hosts of $E$. vogeli are mostly pacas (Agouti paca) on which bush dogs hunt in packs in gallery forest of the northern parts of South America (D'Alessandro et al., 1981; Mayor et al., 2015; Vizcaychipi et al., 2013). Susceptibility of the intermediate hosts may vary from complete resistance to extreme susceptibility, depending on the species and the efficacy of its immune response to a given species of Echinococcus. This influences the infection of definitive hosts in a given area and thus the presence of infective eggs in the environment. Humans may be considered as rather resistant to the Echinococcus spp. metacestode whatever the species. Larval E. multilocularis infection with symptoms close to those observed in humans has been recognized in a number of domestic animals (pigs, horses, cattle, chinchillas...) and in zoo animals or in exotic pets (Deplazes and Eckert, 2001b).

\subsubsection{Incubation period}

For both E. granulosus sl and E. multilocularis, in humans, a very long asymptomatic development of the metacestode (more than one year, sometimes up to 25 years) usually precludes any attribution of the infection of an individual to a given definitive host that could be the source of infection. Humans cannot be a source of infection for definitive hosts or for other humans or intermediate hosts. In domestic animal intermediate hosts of $E$. granulosus sl (CE), especially sheep, cattle and camels, presence of viable metacestode may last several years, until animal slaughtering (or spontaneous death, especially in transhumant communities). The metacestode burden, both in terms of total mass and number of cysts, increases with age (Eckert et al., 2001a). Viscera of older animals have the highest potency of infection when they are eaten by carnivores; modeling in sheep shows a massive accumulation of protoscoleces with the age of sheep (Torgerson et al., 2009). Small mammals, intermediate hosts of E. multilocularis may die from the infection within a few months after infection if they are highly susceptible, or they may be preyed upon by carnivores within one or two years (the usual life span of most of species).
For E. granulosus s.l. and E. multilocularis in the definitive host, as mentioned above, the non-infectious time period between ingestion of protoscoleces by the carnivore from an intermediate host and egg shedding with the feces of the carnivore (called 'pre-patent period') ranges between 4 and 6 weeks (Gemmell et al., 1986). During this prepatent period, Echinococcus spp. antigens or DNA may be found in the carnivore feces; this does not indicate that such feces are infectious to intermediate hosts (including humans). For E. multilocularis, coproantigens may be detected as early as 6 days postinfection in samples of dogs and from 11 days post-infection in samples of cats (Deplazes et al., 1999).

\subsubsection{Period of communicability}

\subsubsection{Shedding levels of E. granulosus}

Only infected definitive hosts, which release $E$. granulosus eggs with their feces, are relevant in terms of transmission of the infection/disease to humans. In the carnivore intestine, the number of worms may vary from a few units to ten thousands, and the number of eggs per proglottid is highly variable, with numbers ranging from as low as 100 to as high as 1500 . On average it is about 600 eggs (Eckert et al., 2001a). The biotic potential may vary widely in different ecological situations and climatic zones: although the individual dogs with high worm burden are less numerous than dogs with low worm burden, very high worm counts may be present in the majority of animals in some areas (such as dogs in Turkana, eastern Africa, or dingoes in Australia) (Baldock et al., 1985). For a given definitive host infected by E. granulosus sl, in the period of egg shedding ('patent' period), infection of environment may thus range from 1000 to 15 million eggs / day. In areas where stray dogs are numerous (Mediterranean, MiddleEast, Central Asia, Indian subcontinent, Tibetan plateau) and close to the animal intermediate hosts (sheep, cattle) and to humans, especially children, this may lead to considerable infectious load of the environment by $E$. granulosus eggs and risk of CE for human populations.

\subsubsection{Shedding levels of $E$. multilocularis}

There are also large variations in worm burdens of $E$. multilocularis in definitive hosts. For example, that in arctic foxes (Alopex lagopus) in Alaska is two orders of magnitude greater than that in the red fox (Vulpes vulpes) in Dakota (Fay, 1973; Rausch and Richards, 1971) low mean worm burdens are the rule in foxes of western Europe, but worm burden is highly overdispersed: $75 \%$ of the total worm population is harbored by less than $15 \%$ of foxes (Raoul et al., 2001). Conversely high mean worm burdens are frequent in dogs of the Tibetan Plateau (Budke et al., 2005a) and in Kazakh and Mongol valleys of Xinjiang, China (Ming et al., 1992; van Kesteren et al., 2015). E. multilocularis egg counts per gram of feces are variable from day to day and may reach values as high as 100,000 (Nonaka et al., 1996). The mean number of eggs per proglottid of the mature E. multilocularis isolated from dogs or foxes is approximately 300 (Thompson and Eckert, 1983). A mathematical model of egg excretion dynamics 
based on parallel experimental infections of various definitive hosts with the same protoscolex load $(20,000$ protoscoleces) has estimated that the mean biotic potential per infected animal was high in foxes $(346,473$ eggs); raccoon dogs (335,361 eggs) and dogs (279,910 eggs) but very low in cats (573 eggs). It also indicated that approximately 114, 42 and 27 eggs per worm were excreted in the feces of dogs, raccoon dogs and foxes, respectively (Kapel et al., 2006). Experimentally, the highest worm burdens in foxes (mean of 16,792) and raccoon dogs (mean of 7930 ) were found at 35 days postinfection then declined to a mean of 331 worms in foxes and 3213 worms in raccoon dogs by day 63 with a further decline to 134 worms in foxes and 67 worms in raccoon dogs by day 90 (Kapel et al., 2006). Because of the preferential cycle between wild animals, with foxes as definitive hosts, and because E. multilocularis parasite cycle is constrained by environmental factors which govern the population of intermediate hosts (climate, land use which favors or not the small mammal populations), egg shedding levels are usually lower for E. multilocularis than E. granulosus, and this may contribute to the lower incidence of AE cases in humans (Eckert et al., 2001a; Eckert et al., 2001c). However, intervention of domestic dogs in the parasite cycle can significantly increase the infection pressure, which may explain the differences in incidence between European endemic areas (where fox is the dominant definitive host) and endemic areas in western China (where dog is usually the dominant definitive host)(Vuitton et al., 2003). In addition, proximity of dogs to water sources in the villages (non-protected wells, streams) used both for drinking water and to water kitchen gardens, the use of dog feces voluntarily or accidentally mixed with cattle dung to fertilize gardens in villages, may increase the risk for humans to ingest $E$. multilocularis eggs. The case of contaminated sludge from water treatment plants used for fertilization of crops/pastures is evoked below.

\subsubsection{Time of shedding}

Dissemination of E. granulosus-infected feces may last from 6 months to 2 years for a single dog. Carnivores may be re-infected, since immunity is only partial; however, both the worm burden and the length of egg shedding are usually decreased compared to the initial infection levels. Egg excretion of E. multilocularis in feces of foxes persists for about 1 to 4 months (Eckert et al., 2001c).

\subsubsection{Distributions}

\subsubsection{Influence of physical constraints}

For E. granulosus as well as E. multilocularis, desiccation is lethal and the limits of temperature tolerance are between $+40^{\circ} \mathrm{C}$ and $-70^{\circ} \mathrm{C}$. Between these two extremes, temperature regulates the maturation/ageing process. Eggs of E. granulosus were shown to survive for more than 200 days at $+7^{\circ} \mathrm{C}$ but only 50 days at $+21^{\circ} \mathrm{C}$ (Gemmell, 1977). Eggs of E. multilocularis were shown to survive for up to 3 and 8 months in the summer and winter in Europe, respectively (Frank, 1989). It is the duration of this seasonal climatic effect on egg survival that, in addition to anthropic factors (which may themselves be linked to climate/altitude) determines the transmission dynamics and geographic prevalence (Gemmell, 1977; Gemmell et al., 1987; Lawson and Gemmell, 1983). Although they display an exquisite sensitivity to dryness, eggs of both species may remain viable for longer periods of time in moist soil and in the surroundings of wells. Eggs of $E$. multilocularis remained viable for about 16 months at $+4^{\circ} \mathrm{C}$ in water in the laboratory (Veit et al., 1995)In France, higher prevalence rates of $E$. multilocularis in voles have been observed in places where fox feces were at higher density and could be washed by rain into the soil (Delattre et al., 1990;Delattre et al.,1988).

\subsubsection{Distribution area from an infected definitive host.}

Although most taeniid eggs usually remain within $180 \mathrm{~m}$ of the site of deposition, some may rapidly disperse over an area of up to 30,000 ha, and the range of dog/fox activities (which, for dogs, may be markedly different depending on their type and use: stray dogs, shepherd dogs, farm dog, pet...) determines egg distribution. Usually, they are dispersed around the infectious feces mostly under the effect of rain, snow, but also ploughing and other human activities. Experimental evidence shows that blowflies are important transport hosts for $T$. pisiformis and $T$. hydatigena: taeniid eggs remain viable after passage through the gut of flies, and blowflies transmit them indirectly to these hosts by their normal activities of vomiting and defecation (Gemmell, 1997; Gemmell et al., 2001b; Lawson and Gemmell, 1990;Lawson and Gemmell, 1985). Birds have also been reported as potential transmission agents of T. saginata (Collins and Pope, 1990). Combined activities of birds and insects may explain Transfer of T. hydatigena eggs over a distance of $60 \mathrm{~km}$ (Torgerson et al., 1995). However, except for a study in Alaska where blowflies (Phormia regina) have been shown experimentally to be capable of transporting eggs (presumably from E. multilocularis) from feces of infected foxes (Schiller, 1954), the demonstration of a significant role of flies has never formally been provided for Echinococcus spp. eggs. Most of the recommendations to populations stress that E. multilocularis eggs are only to be found on grass / vegetables / fruit (berries) growing under $20 \mathrm{~cm}$ above the ground, which might be wrong is flies actually play an important role in dissemination. Eggs may also be transported by rainwater flow, streams, and rivers. Foxes infected with E. multilocularis may disperse eggs with their feces anywhere within their individual areas of activity, in rural and in urban areas. In Europe, it has been observed that red foxes tend to deposit larger densities of feces on field borders, road and path verges, molehills and Arvicola terrestris tumuli than on meadows, on fields or other landscape structures where they are found at lower density (Giraudoux, 1991; Labhardt, 1990). Foxes living in urban, suburban and rural situations (e.g., in Hokkaido, Japan, or in Europe) may contaminate plants and soil in gardens and yards. Since red foxes are using feces and urine as olfactory markers, they tend to deposit feces also on garbage material, such as glass bottles, plastic material and others (Labhardt, 1990). Foxes may also contaminate vegetation used for food by people. For example, in Alaska 
on the tundra, and in western China villages and Tibetan plateau campsites, a variety of plant species, used as food, condiments, and/or traditional medicine, are collected by the populations, eaten immediately and/or stored for later consumption. Voles also feed on such plants, which contributes to the maintenance of the parasite cycle in nature. Dandelions (Taraxacum officinale) are frequently collected and eaten as raw salad in Franche-Comté, France, in grassland areas where over $90 \%$ of fox feces are scattered (Giraudoux, 1991). It is assumed that eggs of $E$. multilocularis can be dispersed with plants contaminated with droppings of infected definitive hosts. In Switzerland, E. multilocularis infections were observed in pigs and in monkey colonies of a zoo after feeding of grass harvested from meadows accessible to infected foxes (Deplazes and Eckert, 2001b). Infection of pigs in 4 large-scale husbandries was also observed in Germany, likely due to hay or straw exposed to infected foxes (Böttcher et al., 2013). Pig and horse infections were reported in Hokkaido, the AE endemic area of Japan, as early as the 1980-90s and rearing cattle or pig (sharing a similar environment) was a significant risk factor for AE in Hokkaido residents (Kaji et al., 1993; Kamiya et al., 1987; Yamamoto et al., 2001). Humans can contract Echinococcus infections by direct contact with infected definitive hosts, or indirectly through food, water and objects contaminated with eggs of the parasite. However, exact information on the actual significance of the direct and indirect ways of transmission is scarce because studies on this topic are difficult to perform and have been hampered by the fact that the eggs of Echinococcus and Taenia species cannot be distinguished. Current availability of reliable PCR techniques should allow significant progress in this field (see section 2.0 below).

1.3.6 Factors contributing to the transmission dynamics of Echinococcus spp

(Figure 5). A number of factors are responsible for the geographic heterogeneity of Echinococcus spp. distribution in the world, and they may be affected by global environmental change (Cadavid Restrepo et al., 2016)
Factors which influence transmission of Echinococcus spp. may be summarized as follows (Figures $6 \mathrm{~A}$ and $\mathrm{B}$ ):

1) Intrinsic factors, that include biotic factors common to Echinococcus spp. or specific to one given species, and innate and acquired immunity of the definitive and intermediated hosts;

2) extrinsic factors, that include environmental temperature and humidity, agents able to disperse eggs from feces into environment, and predator-prey relationship between definitive and intermediate hosts (mainly for E. multilocularis)(Viel et al., 1999); and

3) socio-behavioral factors, that include farming practices (for E. granulosus) and more generally land use [for E. multilocularis; see (Raoul et al., 2015)], feeding behavior of domestic definitive and intermediate hosts, legislation, meat inspection, and their enforcement (for $E$. granulosus), and level of awareness of human population (for both). Mathematical models have been established which tend to take all these factors into account to describe and/or predict transmission dynamics of CE and AE [for details see (Gemmell et al., 2001b; Roberts et al., 1986)]. They may help determine the potential risk of water infection by eggs in a given area. Regarding water drinking, it may be noticed that in emerging countries such as rural China, tap water consumption has markedly increased within the last 2 decades as shown by a recent survey in Liaoning (one of the north-eastern provinces endemic for $\mathrm{AE}$ ) which showed that $73 \%$ of village households used tap water in 2014-2015 (Mong et al., 2011). However, quality/safety of tap water may be quite different, even in the same region: among 15 cities of Xinjiang (western China, endemic for both $\mathrm{CE}$ and $\mathrm{AE}$ ), in 2011, tap water was Cryptosporidium parvum positive in samples collected from 4 cities and negative from 11 of them (Xie, 2016;Xie et al., 2016); drinking bottled 'purified water', quite popular currently in China, and often replacing the traditional (and safe) tea prepared with boiled water, may not prevent infection because of differences in quality standards and/or methods actually used for the 'purification'. 


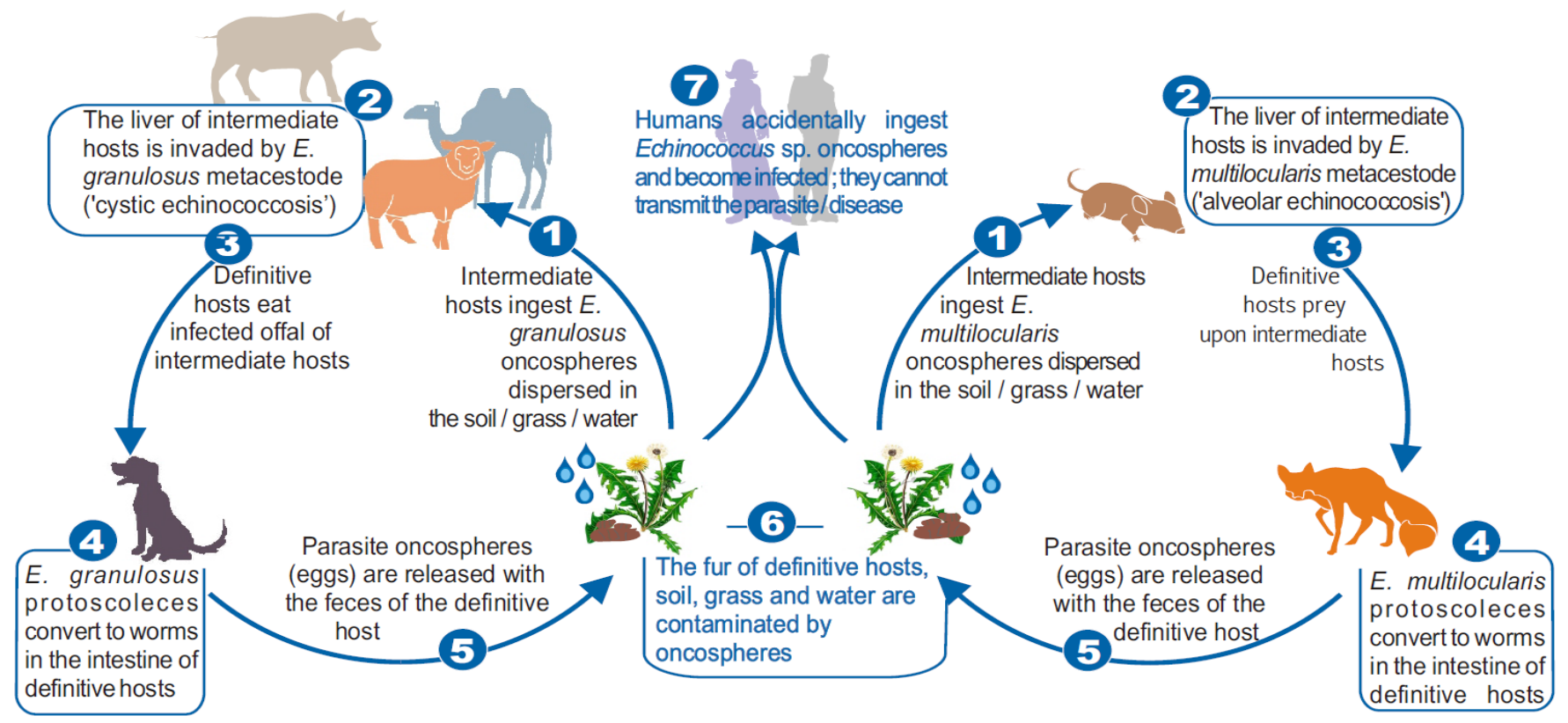

Figure 5. Parasite cycle of Echinococcus granulosus sensu lato (on the left) and of Echinococcus multilocularis (on the right)

Drawing by Sophie Muraccioli, Department of Communication, University Hospital, Besançon, France

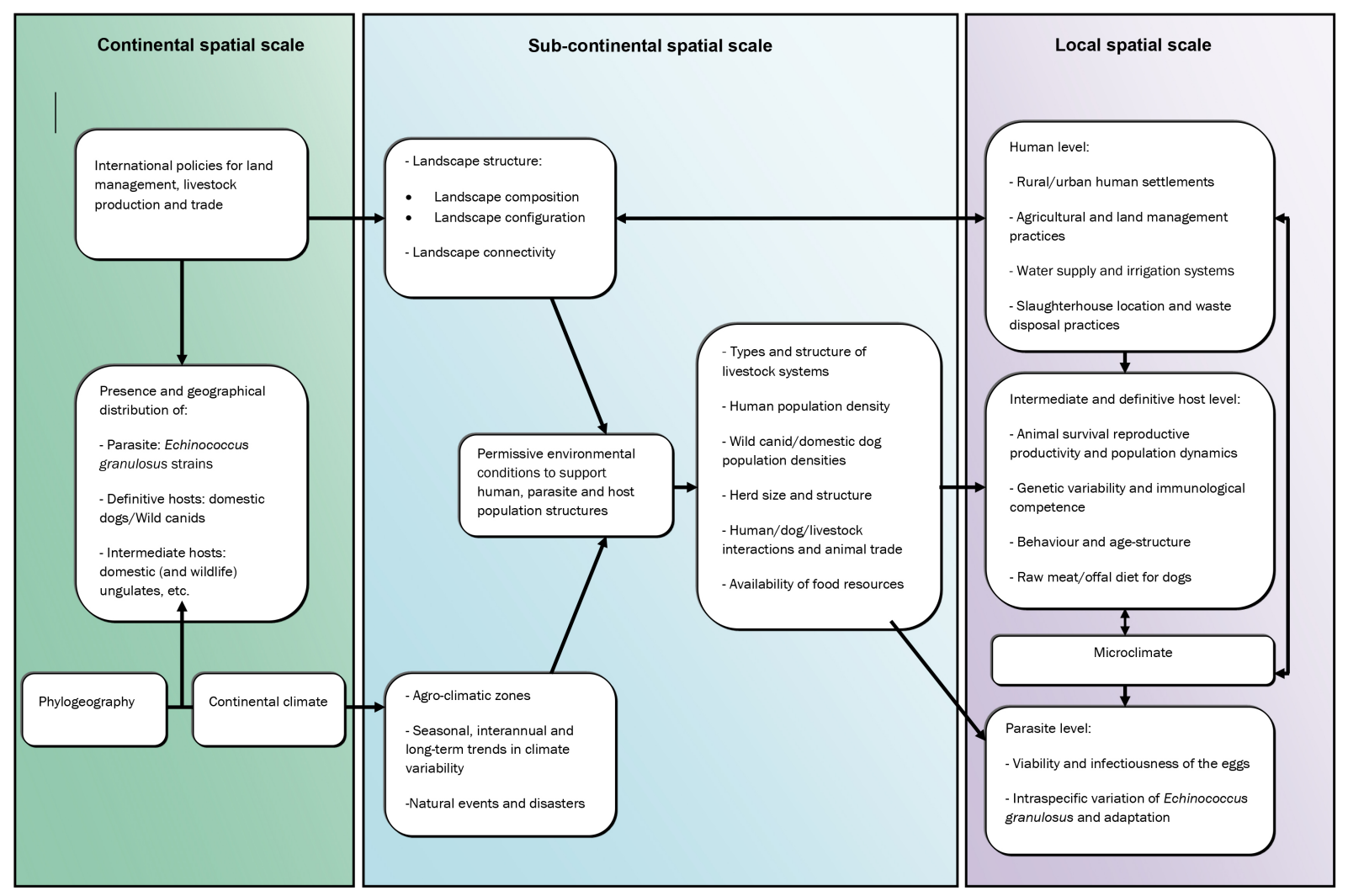

Figure 6A. Factors which influence transmission of Echinococcus spp. (after Cadavid Restrepo et al., Cadavid Restrepo et al., 2016) with modifications. 


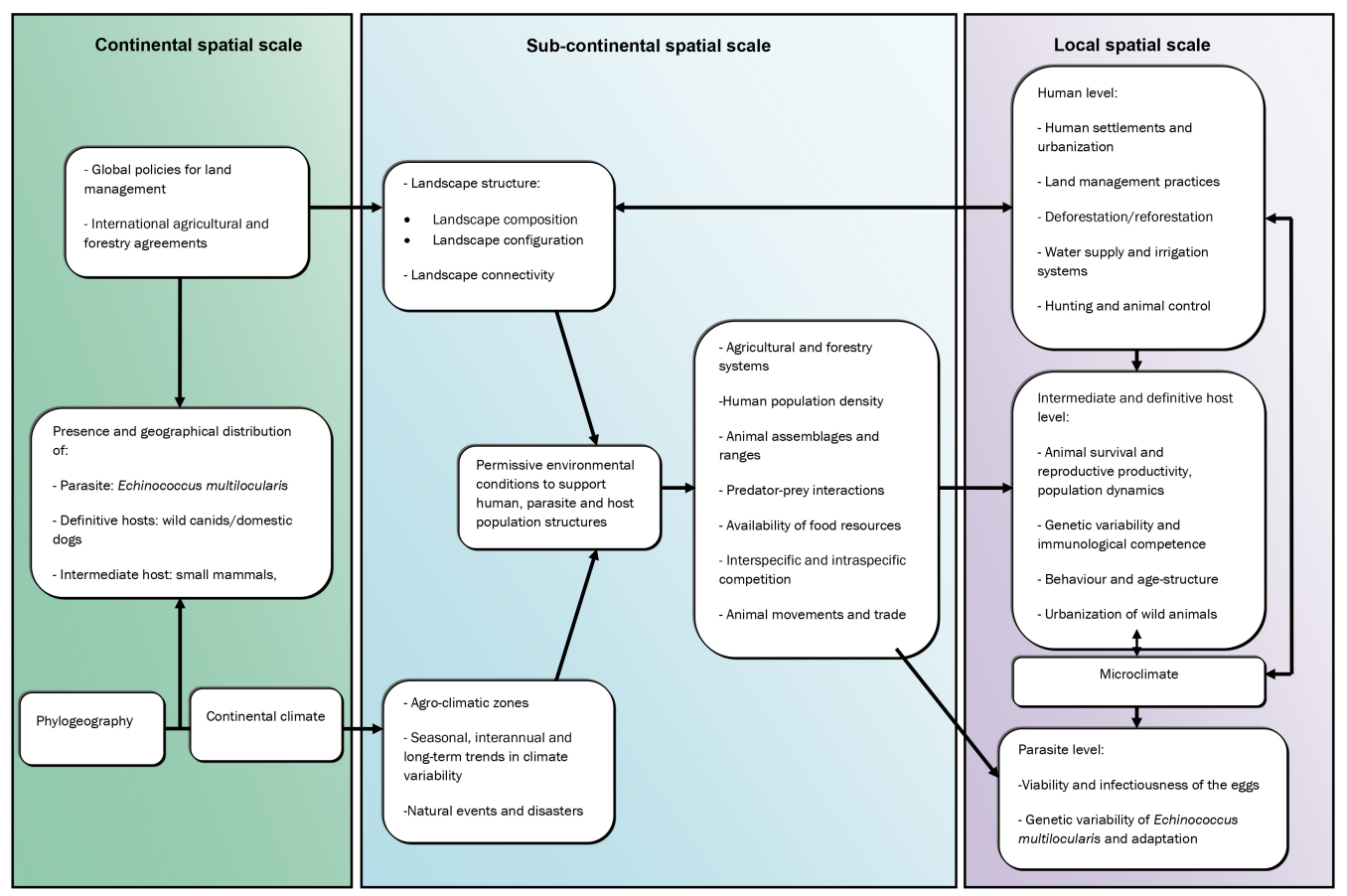

Figure $\widetilde{6}$. Factors which influence transmission of Echinococcus spp. (after Cadavid Restrepo et al., (Cadavid Restrepo et al., 2016) with modifications.

Among socio-behavioral factors, pastoralism and transhumance have been pointed out as important risk factors, for a number of reasons (MacPherson, 2001). Transhumant pastoralists have one of the lowest socioeconomic levels in the world in terms of education, income and standard of living. Their living in tents, yurts or shacks, herding occupation, close association with their animals, the sharing of water sources with dogs, the almost complete lack of piped water and abattoirs and the poor sanitary conditions, provide ideal conditions for parasitic diseases, including CE. Premature livestock deaths in these communities also provide scavenging opportunities for dogs during the spring and autumn migrations. In Xinjiang, China, as an example, most herdsmen are Kazak and Mongolian and move twice a year, during spring (April or May) and autumn (September or October), towards summer and winter pasture areas, at high and low altitudes, respectively. Most farmers can use tap-water in their winter houses, and animals have shelters in the winter settlements. In summer pastures they usually install their yurts in an open area close to a stream or a river that may be infected by Echinococcus eggs shed by the family dogs. Water drinking is, however, unlikely the main source of infection, because of the deeply ensconced habit of boiling water for tea to drink. Until relatively recently, CE (as well as $\mathrm{AE}$ in transhumant communities of the Tibetan plateau and central Asia) remained unrecorded because transhumant peoples spent most of their time in remote areas where, prior to the 1950s, there were invariably no veterinary, medical, educational facilities nor trained personnel. During the past 40 years with the introduction of primary care and hospital facilities into areas inhabited by transhumant peoples, the perception of the public health importance of $\mathrm{CE}$ has been dramatically revised. In parts of Africa, in central Asia and western China, CE which was previously unrecorded is now better identified because of the introduction of improved medical services. The nomadic communities of western China are currently included in the Chinese national control program (MacPherson, 2001; The Central People's Government of the People's Republic of China, 2014).

\subsubsection{Gender for CE and AE}

Although hospital reports (especially from Europe but also from low-income countries) do not show big differences in terms of gender (Pawlowski et al., 2001) perhaps because men are more likely to undergo hospital treatment than women, in most of the highly endemic areas where mass screenings have been performed women are more infected than men, both for CE and AE. This may be only due to behavioral factors (such as caring for dogs, which was often correlated to woman susceptibility in risk factor analyses) (Craig et al., 2000); specific hormonal factors may also be evoked. Pregnant women have been reported at risk of metastatic dissemination of AE (Yang et al., 2005); this might be due to the relative state of immune tolerance which develops in this condition; however, no systematic studies have been published. In addition, antiparasitic treatment by benzimidazoles must be withdrawn during the first trimester of pregnancy because of teratogenic effects, which may contribute to the risk of metacestode growth in women with already diagnosed and treated $\mathrm{AE}$. 
Specificities in the occurrence and/or progression of CE in patients with immunosuppression are not clear; a few cases of associations have been reported, especially in patients with AIDS/HIV infection, but also with therapeutic immune suppression [e.g. (Capdevielle, 1984; Erayman et al., 2011; Gruener et al., 2008; Ran et al., 2016)] but there is no published systematic study that would be convincing of a significant enhancing effect of immune suppression on the incidence or the course of CE (such as faster cyst growth, multiple organ dissemination).

Genetic, especially within the HLA system, and immunological particularities have been associated with the occurrence and/or progression of AE lesions in humans (Eiermann et al., 1998). Effects of immune suppression on E. multilocularis growth have been well studied in experimental animals (Vuitton and Gottstein, 2010). First evidence of the facilitating effect of immune suppression on $\mathrm{AE}$ lesion development in humans came from the first $\mathrm{AE}$ patients who received liver allo-transplant to treat their disease (Bresson-Hadni et al., 1999; Koch et al., 2003). Fast progression of the lesions in a patient with AIDS (Sailer et al., 1997) and conversely the protective effect of efficacious anti-HIV treatment in another patient (Zingg et al., 2004) have confirmed the role of immune suppression in patients with $\mathrm{AE}$. Since the beginning of the 21st century, a number of $\mathrm{AE}$ cases have been reported in patients who received other kinds of organ transplantation and/or were treated with imunosuppresive drugs for malignant or chronic inflammatory diseases (Dentan et al., 2012; Gaultier et al., 2009; Geyer et al., 2011; Gruener et al., 2008; Kayacan et al., 2008; Kern et al., 2011) The increase in the occurrence of $\mathrm{AE}$ in such patients was evidenced in a systematic study using the data from the population-based AE French registry database (1982-2012) (Chauchet et al., 2014): 50 patients were found with such immunosuppressionassociated (IS) conditions before or at AE diagnosis, among 509 AE cases diagnosed from 1982 to 2012. There was a significant increase in $\mathrm{AE}$ incidence in such patients, and significantly higher increase than in non-IS cases between the last 2 decades. Acquired therapeutic immunosuppression appears to be the main factor for the occurrence of $\mathrm{AE}$ and its fast progression in the patients. Combined chemotherapy for cancer or malignant hematological disorders is most often involved, followed by corticosteroids. Biotherapy such as anti-Tumor-NecrosisFactor (TNF) agents given together with 2 or more immunosuppressive drugs is particularly at risk. Unusual presenting symptoms and negative serology may contribute to delayed diagnosis and wrong therapeutic management in these patients (Chauchet et al., 2014). It is likely that the number of patients with underlying immunosuppressionassociated conditions and incidental AE-detection will increase in Europe but also in other endemic areas such as China in the future, because of treatment intensification in patients with chronic inflammatory diseases and malignant disorders, and wider use of new therapeutic regimens, including bio-therapeutic agents.

\subsection{Population and Individual Control Measures}

\subsubsection{Treatment options}

Compared to most of parasitic diseases and/or zoonoses, for which an appropriate and rapidly efficacious medical treatment is available, echinococcosis can rarely be cured by anti-parasite therapy alone, safely and within an acceptable time schedule, and the available drugs are extremely limited (Brunetti et al., 2010; Gottstein et al., 2015; Junghanss et al., 2008). In addition, there have been nearly no well-designed clinical trials for any medical treatment modality in either form of echinococcosis (Kern, 2006). Only 2 benzimidazole compounds, used since the beginning of the 1980s have proven effective against CE and AE: mebendazole (MBZ) $(4.5 \mathrm{~g} / \mathrm{d})$ and albendazole (ABZ) (10 to $15 \mathrm{mg} / \mathrm{kg} / \mathrm{d}$ ) (Horton, 2003; WHO Informal Working Group on Echinococcosis, 1996). Both drugs have a poor bio-availability, mostly due to poor intestinal absorption; the most practical way to improve absorption is to combine $\mathrm{ABZ}$ with a fatty meal. $\mathrm{ABZ}$ (i.e. ABZ sulfoxide, the active compound originating from hepatic metabolism), however, may reach higher plasma levels than MBZ. For this reason, and because it is approved by the drug agencies of most countries, opposite to MBZ, ABZ is the most widely used drug for the treatment of echinococcosis. Both MBZ and ABZ must be given continuously, without interruption, for the period of treatment assigned to each case depending on the type of disease and treatment association. For AE, when radical resection is not applicable, ABZ must be administered for life under strict medical follow-up, and whenever possible the measurement of the active metabolite of the ABZ, ABZ sulfoxide (Brunetti et al., 2010) should be performed. Side-effects are observed with both drugs, especially hepatotoxicity and leukopenia which may be life-threatening and may lead to definitive treatment interruption. Despite multiple studies of promising compounds, there is currently no alternative treatment (Hemphill et al., 2014; Vuitton and BressonHadni, 2014). For both diseases, the therapeutic approach should be multidisciplinary since in most cases it associates drug and interventional treatments.

\subsubsection{CE and $\mathrm{AE}$ interventional treatment in humans}

Treatment of both $\mathrm{CE}$ and $\mathrm{AE}$ has long relied on surgery, with the aim of totally removing the parasitic 'tumor' from the infected liver or lung. In CE, besides such 'radical' removal of the lesions (total cystectomy), partial removal of the cyst associated with sterilization of the germinal layer and protoscoleces of $E$. granulosus sl is still a common attitude of surgeons in most endemic areas, despite the risk of recurrence and/or dissemination of cysts. In selected CE patients/cysts, percutaneous puncture of the cyst, followed by aspiration of the cyst fluid, injection of protoscolecidal compounds (usually hypertonic saline or alcohol) and re-aspiration of the fluid (PAIR) has demonstrated its efficacy and safety (Brunetti et al., 2010; Pawlowski et al., 2001; Tamarozzi et al., 2014; WHOInformal Working Group on Echinococcosis, 2001). Perendoscopic procedures (Endoscopic retrograde cholangio-pancreatography, ERCP) may also be used to 
treat biliary complications, especially biliary fistulae after surgery for complicated cysts. In $\mathrm{AE}$, partial resection of $\mathrm{AE}$ lesions was commonly performed, associated with surgical biliary drainage, until retrospective analysis of cases from European teams showed that such interventions were followed by an increased rate of complications and decreased survival of the patients (Buttenschoen et al., 2009; Kadry et al., 2005). Palliative surgical interventions may be replaced by percutaneous or perendoscopic interventions of drainage and/or stenting, especially to alleviate complications of biliary obstruction or to treat bacterial infection of the central necrotic cavity in $\mathrm{AE}$ lesions (Ambregna et al., 2017; Bresson-Hadni et al., 2006; Vuitton et al., 2016). Whenever possible, any intervention should be associated with ABZ treatment: 1 to 3 months after any interventions for $\mathrm{CE}, 2$ years after radical resection for AE. However, such a treatment has never been properly evaluated in $\mathrm{CE}$, and is rarely used in most of highly endemic areas of $\mathrm{CE}$, because of economic constraints or lack of availability of the drug.

\subsubsection{Vaccines}

Vaccines are currently not applicable to humans. However, significant progress has been made in this field by the development of the Eg95 vaccine applicable to sheep, the main intermediate host of CE. Vaccination against $C E$ using a defined recombinant antigen, the oncospheral protein EG95, has been shown to induce a protective response against infection in animal intermediate hosts of E. granulosus (Lightowlers et al., 1996)(Lightowlers et al., 1996), yielding overall protection rates of $97 \%$ in sheep (Gauci et al., 2005; Lightowlers, 2006; Lightowlers et al., 1996) and of 88-96\% in cattle (Heath et al., 2012). Highly effective vaccines against $E$. granulosus are thus available to prevent infection in its animal intermediate hosts. Application of vaccines on large scale, together with PZQ in the parasites' definitive hosts, have already provided new opportunities for the control of $\mathrm{CE}$ and a reduction of its global burden in humans (Larrieu et al., 2015; Larrieu et al., 2013). Efficiency of Eg95 appears not to be affected by the currently known genetic diversity within E. granulosus sl. Nevertheless, despite a number of field trials in several endemic areas, at this time there are still open questions and points that need further elucidation with regard to vaccination. For instance, there is no clear evidence of exactly how long immunity lasts in animals vaccinated with EG95 or if there is a differential effect in case of repeated reinfection or of absence of reinfection, and/or if more booster injections are needed. Ongoing larger scale vaccination studies should answer such questions; results in China and South America look promising. The vaccine is registered, produced and commercially available in China. The adaptation of Eg95 and development of other types of vaccines applicable to $E$. multilocularis infection in humans is currently ongoing in experimental intermediate hosts (Dang et al., 2012; Gottstein et al., 2015; Vuitton and Gottstein, 2010). On the other hand, vaccines that could be applicable to the definitive hosts would be more manageable in terms of acceptability and administration (Kouguchi et al., 2013; Zhang et al., 2006; Zhang and McManus, 2008). However, complementary studies are clearly necessary to reach this goal (Torgerson, 2009).

\subsubsection{Control of definitive and intermediate animal hosts}

In echinococcosis, humans are 'dead-end hosts' (i.e. 'intermediate hosts' that cannot ensure a proper functioning of the parasite cycle); there are no vectors and the control programs mainly address the animal 'definitive hosts', i.e. carnivores that harbor the adult worms in their intestine and are directly responsible for infection to humans though egg dissemination. Except vaccination of domestic animals, already described above, interventions on the animal 'intermediate hosts', i.e. domestic animals or small mammals which harbor the larval stage, are more limited.

Control programs for CE are complex, with multiple targets, and require considerable investment of time (minimum 10 years of "attack phase" followed by a "consolidation" and "maintenance" phase) and resources (Eckert et al., 2001a; Huang et al., 2011), together with a consensual coordination of various actors (professionals and decision-makers in human and animal health, police, legislation, education) (Gemmell et al., 2001a). The principal points of intervention are: i) veterinary public health actions such as control of livestock movements and slaughter, including inspection of organs and proper disposal of infected viscera and dead animals; ii) registration of owned dog and control of stray dog population; however dog culling practices should be carefully evaluated (Johansen and Penrith, 2009); iii) accurate estimation of baseline epidemiological data in the animal and human population; vi) regular treatment of dogs with PZQ, at least every 6 weeks; v) education of the owners about safe feeding of dogs and animal husbandry, and of the whole community about the purpose and importance of the program; vi) making CE a notifiable disease and introduce an appropriate supporting legislation (Barnes et al., 2012; Torgerson et al., 2011).

\subsubsection{Echinococcus spp. chemotherapy in definitive hosts}

Praziquantel (PZQ) has long been the only drug with a demonstrated effect on Echinococcus spp. adult worms, thus of possible use for deworming definitive hosts, dogs and fox, and interrupting the parasite cycle (Gemmell et al., 1977), and it is still the drug of reference. Epsiquantel and emodepside are alternative drugs; however, studies on the efficacy of emodepside were performed using emodepside and praziquantel in combination, i.e. Profender tablets ${ }^{\circledR}$, in dogs experimentally infected with E. granulosus or $E$. multilocularis and Profender topical solution ${ }^{\circledR}$ in cats infected with E. multilocularis, respectively (Charles et al., 2005; Schroeder et al., 2009). PZQ (5.0 mg/kg/bw) given orally is highly effective against immature and mature intestinal stages of E. granulosus, E. multilocularis, Taenia species and some other Cestode genera (Eckert et al., 2001a; Oakley, 1991). However, the drug is not ovicidal (Thakur et al., 1979), i.e. it only kills the worms, and has no effect on the eggs/oncospheres which may be released in the environment and remain infectious after carnivore 
deworming. Carnivore feces should thus be safely destroyed during at least 3 days after deworming. In addition, to be fully effective PZQ should be orally administered to dogs every 6 weeks (i.e. 8-9 times a year). Both measures are very problematic in remote areas and transhumant populations and are often not followed, which significantly reduces the impact of PZQ administration (Larrieu and Zanini, 2012; van Kesteren et al., 2015). Application to E. multilocularis infection in foxes has been developed by using baits with PZQ (Schelling et al., 1997; Takahashi et al., 2013); although it may be especially useful in peri-urban and urban areas, it is an expensive procedures, which requires appropriate logistics, and a strong support by the local authorities (Hegglin and Deplazes, 2008). In addition, to be fully efficacious, it should be repeated several times a year. Results obtained in middle-size cities in France are rather contrasted and appear to depend on the density of infected foxes and small mammals in the periphery of the baited area (Comte et al., 2013; Umhang et al., 2014). The strategy used to control $E$. multilocularis in definitive hosts should take the specific weight of each possible definitive host in a given area into account; for instance, in Europe, high densities of dogs and cats as pets can easily outweigh low infections rates; contribution of dogs to environmental contamination with E. multilocularis eggs may be estimated at $4-19 \%$, while the contribution of domestic cats would be rather insignificant $(<0.3 \%)$ due to low parasite reproduction in this species (Hegglin and Deplazes, 2013). To be fully efficient, fox baiting campaigns should be only implemented if longlasting and intense baiting may be ensured; at least at the beginning of a deworming program, the intervals between baiting campaigns should not be longer than the period of prepatency in foxes, i.e. 1 month; in addition, modelling indicates that baiting intervention should focus on densely populated highly endemic areas (Hegglin and Deplazes, 2013; Hegglin and Deplazes, 2008).

\subsubsection{Other interventions on the definitive host}

Inter-regional and international transit of possible definitive hosts of $E$. multilocularis is a threat to countries/regions which are still considered to be free of the cestode. Twelve pairs of red foxes which were imported to Rebun Island/Japan from the Kurile Islands between 1924 and 1926 have been responsible for the spread of the parasite to $90 \%$ of Hokkaido in 1991, and apparently further south to Honshu Island (Kimura et al., 1999; Satoh et al., 2005) and of more than 300 human cases of AE (Kawamura et al., 2011). In the USA, illegal shipments of red foxes and coyotes originating from Indiana and Ohio were confiscated in South Carolina; E. multilocularis was identified in red foxes that were to be released into foxhunting enclosures in the south-eastern states (Davidson et al., 1992). Genetic analysis of E. multilocularis strains found in carnivores in Alberta highly suggest that animal and subsequent human infection diagnosed recently in this province was imported from Europe, and not maintained locally with the Alaskan/Arctic strain (Massolo et al., 2014). It might be recommended that all potential definitive hosts of $E$. multilocularis in national or international transit from endemic to non-endemic regions should: a) be treated before shipment in a quarantine unit on two consecutive days with therapeutic doses of PZQ; b) have valid certificates of the cestode-free status of the state/country of origin signed by the veterinary authorities; c) have an import license (specifying details of transport requirements) by the veterinary authorities in the state/country of destination; and d) be transported in separate sealed units so that removal of the animals breaks the seals. PZQ treatment is currently in use for the entry of dogs into the United Kingdom, Ireland, Malta and Finland in Europe, but this regulation is regularly questioned (Goodfellow et al., 2006; Torgerson and Craig, 2009).

\subsubsection{Interventions on the intermediate hosts}

Besides vaccination of sheep and cattle (see above: D2), interventions on the intermediate hosts of $E$. granulosus sl consist in avoiding ingestion of their viscera by carnivore definitive hosts after slaughtering. This is achieved by meat inspection, effective disposal of offal at abattoirs, prevention of clandestine leakage of offal and permanent surveillance of livestock at slaughtering (Gemmell et al., 2001a). When organized and controlled slaughtering is not possible, e.g. in transhumant populations, health education is essential and should provide practical and cheap solutions to shepherds and their families to prevent offal consumptions by the family dog or by stray dogs. Educational and meat hygiene components may not modify transmission, but will contribute generally towards improving standards of living and an understanding of the health problem; it may also facilitate the implementation of other control measures by enhancing the community participation in the attack phase of a control campaign (Gemmell et al., 2001a). Burning and/or burying sheep or cattle livers and lungs found with cysts at slaughtering are usually recommended (Parodi et al., 2001). Boiling livers and lungs which contain CE cysts for 30 minutes appears to be a simple, efficient and energy- and time-saving way to kill the infectious protoscoleces and to prevent dog infection (Li et al., 2014). The control of small mammal intermediate hosts in order to limit E. multilocularis transmission has never been attempted except where they are agricultural pests and for that reason (Delattre and Giraudoux, 2005). Poisoning campaigns (using anticoagulant drugs, such as bromadiolone) raise inacceptable environmental and conservation issues, especially if applied on such a large scale they are effective by both decreasing small mammal populations and leading to secondary poisoning of foxes (or dogs) that prey on intoxicated small mammals (Coeurdassier et al., 2014; Jacquot et al., 2013; Raoul et al., 2003). Modifications of the landscape through various modalities of land use have been shown to enhance or conversely to limit the occurrence of high densities of those small mammals which are intermediate hosts for E. multilocularis (Delattre et al., 1992; Giraudoux, 1991; Graham et al., 2004; Wang et al., 2006; Wang et al., 2004). However, no specific intervention on the landscape has ever been launched only to prevent $\mathrm{AE}$. 


\subsubsection{Hygiene measures}

Treatment of human cases is only relevant at the individual level. As infected humans do not take part in the transmission of the disease, this treatment has no impact on the infection of animal hosts and/or of the environment. As regard to the single (human) individual, prevention of $\mathrm{CE}$ and $\mathrm{AE}$ (i.e. avoiding the ingestion of infective eggs shed by the carnivores) relies only on general hygienic measures, such as washing hands before eating, avoiding contact between mouth and non-washed hands, thorough washing of raw vegetables, avoiding direct contact with possibly infected carnivores (dogs and foxes), and use of a safe water source (see below). As eggs of all species of Echinococcus spp. are sensitive to heating, boiling water and cooking vegetables, fruit and other plants possibly infected by carnivore egg-containing feces are the only measures to completely inactivate infectious eggs and prevent the diseases. Freezing (at temperatures reached by family freezers) does kill the eggs and thus does not protect humans against CE or AE (Eckert et al., 2001b).

\subsection{Environmental Occurrence and Persistence}

\subsection{Detection Methods}

\subsubsection{Detection of Echinococcus spp. eggs}

Handling of material containing viable eggs of Echinococcus spp. represents an infection risk for humans. Therefore, special safety precautions have to be observed (Eckert et al., 2001b). Eggs can be detected in fecal samples using routine flotation techniques. Echinococcus spp. eggs are ovoid, $30 \mu \mathrm{m}-40 \mu \mathrm{m}$ diameter, and consist of a hexacanth embryo, the oncosphere, i.e. the first larval stage, surrounded by several envelopes, the most noticeable one being the highly resistant oncosphere membrane and a keratinized embryophore, which gives the egg a dark striated appearance (see Figure 4). The outer capsule quickly disappears once the eggs are liberated from the host. The eggs of Echinococcus spp. are morphologically indistinguishable to those of other tapeworms of the genus Taenia (Thompson and McManus, 2001). However, proglottids of $E$. granulosus spontaneously discharged by dogs and detected mostly on the surface of fresh fecal samples may allow a correct morphological diagnosis, if they are in good condition (Eckert et al., 2001a; Thompson and McManus, 2001). This is a rather rare situation, and proglottid identification is not applicable to the study of environmental (including water) samples. However, flotation/sieving may be the first step of identification, especially using molecular methods, and it can be modified by using larger sieves (Conraths and Deplazes, 2015; Mathis et al., 1996).

\subsubsection{Detection of Echinococcus spp. antigens}

Several groups have described ELISAs for the detection of coproantigens released by cestodes, including Taenia species of dogs and humans, E. granulosus of dogs and $E$. multilocularis of foxes, dogs and cats (Allan and Craig, 2006; Eckert et al., 2001a). Coproantigens highly specific for the genus Echinococcus could be detected by antibody capture ELISA in dogs experimentally infected with $E$. granulosus or E. multilocularis by 5-10 days post infection, i.e. in the pre-patent period. Such detection thus does not depend on presence of eggs, and may hardly be used as a marker of environmental infection which actually depends on the presence of viable/infective eggs. Some of these techniques have been evaluated on fecal samples collected either in the rectum of dogs or in the area of dog/fox defecation and, for the latter, studied for their reliability, depending on the time elapsed between defecation and collection of samples. Most of the techniques had very good sensitivity and specificity when used on rectal samples, especially when the worm load was high; however, the techniques have often been used without adequate quality control and proper definition of their performance characteristics, while both sensitivity and specificity turned to moderate or low when they were used for the field work on feces collected in the environment and/or from dogs with a rather low parasite load (Eckert, 2003; Hartnack et al., 2013). In addition, in those areas where both $E$. granulosus and E. multilocularis co-exist (such as Turkey or western China), copro-antigen detection only provides information at the genus level. In addition to home-made tests available in specialized labs working on Echinococcus spp. infections, at least two ELISA kits have been commercially available (Echinococcus-ELISA from Genzyme-Virotech $\mathrm{GmbH}$, Rüsselsheim, Germany; Chekit ${ }^{\circledR}$ Echinotest from Dr Bommeli AG, Liebefeld-Bern, Switzerland) in Europe, and several ones are produced in China (e.g. Haitai, Tiankang and Combined Kits), with various degrees of sensitivity/specificity; comparisons may be found in (Hartnack et al., 2013; Huang et al., 2014). Although coproantigen tests can be used for identifying infected dogs during control programs, their use on fecal samples with varying degrees of desiccation in the environment may only give an approximate of the infection pressure in a given area. Use of coproantigens to detect the presence of Echinococcus spp. eggs in environmental samples is even more problematic.

\subsubsection{Detection of Echinococcus spp. DNA}

Choice of appropriate sequences to identify DNA of the various species of Echinococcus currently provides the best, albeit more expensive, approach to the detection of parasitic materials in the environment. Several techniques have been proposed after the first Echinococcus spp. identifications in definitive host feces using molecular biology (Bretagne et al., 1993; McManus and Rishi, 1989) and their reliability benefited from the use of nested PCR (Dinkel et al., 1998; Jiang et al., 2012; Karamon, 2014; Mobedi et al., 2013). As for copro-antigens, and because of the interference with proteases in fecal materials, some of the initially developed techniques on total fecal samples (without egg isolation) often proved to be unreliable when used in field work, on low quality samples or after freezethawing (a precaution recommended to avoid human infection in research labs when working on Echinococcus spp. samples) (Klein et al., 2014). Primary isolation of eggs, 
followed by parasite DNA identification and characterization was first initiated by the Zurich team (Mathis et al., 1996) it is an approach which both increases the sensitivity and specificity, and takes only the infective agents (the eggs) into account (Chaâbane-Banaoues et al., 2016; Széll et al., 2014). Comparison of two extraction protocols, one based on sieving of fecal material and one using targeted DNA sampling and of four methods of molecular detection of $E$. multilocularis in infected fox feces (one conventional PCR and three real-time PCR methods) has recently been reported (Øines et al., 2014): the use of real-time PCR combined with targeted DNA extraction improves the sensitivity of E. multilocularis detection in fecal samples containing low numbers of $E$. multilocularis eggs; results also indicate the importance of replicates of the PCR-reactions when pathogen levels are low. Quantification of the parasite load in fecal samples collected in the environment is also made possible thanks to real-time PCR (Knapp et al., 2014). Techniques which combine the identification of several Echinococcus species and of the animal species of the collected feces (multiplex PCR)(Boubaker et al., 2013; Dinkel et al., 2011 ; Knapp et al., 2016; Liu et al., 2015; Trachsel et al., 2007) may provide more accurate data for epidemiological studies, especially in areas where several Echinococcus species and several definitive hosts co-exist and in the context of control. However, even though molecular techniques appear currently to be the most appropriate to study Echinococcus infection in the environment and their automation has been developed and evaluated (Isaksson et al., 2014), there are very few studies on the eggs in the environment and only one on-going study (unpublished yet) on wastewater (Conraths and Deplazes, 2015; Lass et al., 2015; Szostakowska et al., 2014).

\subsection{Data on Occurrence in the Environment}

\subsubsection{Excreta in environment}

There have been limited studies on the presence of Echinococcus spp. eggs in environment (except for carnivore feces collected in the environment). More specifically, except one study in water samples from open waterholes in Turkana, Kenya, in 1988 (Craig et al., 1988), there are no published data on the presence of Echinococcus spp. eggs in sewage, sludge, surface waters, ground water, drinking water, or soil irrigation water; studies in fish, shellfish (and/or sea water) would not be relevant, since such species are not infected by Echinococcus spp. The limitation has long been the impossibility to distinguish between taeniid eggs, and it was long considered that this type of study was just not possible. Even a tedious work of egg numbering under the microscope would have provided scientifically non-relevant results, because of the presence of eggs from species noninfective to humans such as Taenia pisiformis or Taenia hydatigena or from species responsible for very different diseases such as Taenia saginata or Taenia solium. Until recently, most of the evidence for a role of water in $\mathrm{CE}$ and/or AE transmission has been indirect, and has come from correlations observed in cross-sectional epidemiological studies. Introduction of the detection of copro-antigens, in the 1990s, then of the detection of parasite DNA using various types of PCR has made such studies possible, but they are still very limited in number and in the type of milieu. In Iakutia, in the Soviet era, the incidence of 'hydatid disease' (both cystic and alveolar) was three times greater in populations supplied with water from certain lakes as compared with those using water from rivers (Martynenko et al., 1986; Martynenko et al., 1983). High prevalence levels of echinococcosis in Russian Arctic, Siberia and the Far East, for the period 2000-2011, compared with national levels in Russia was recently attributed, albeit without evidence, to poor quality of centralized water supplies and sewage systems, and biological contamination of drinking water (Dudarev et al., 2013). Hospital records from Kyrgyzstan clearly show a lower risk of CE for people who are more likely to use well water as their water supply, rather than stream water (Torgerson et al., 2003). In Ningxia, China, higher AE prevalence among people without access to tap or well water was observed by univariate but not multivariate statistics (Pleydell et al., 2008). Other studies in Ningxia claim the possible role of water but based on epidemiological studies they failed to detect a statistically significant effect from various water sources, except for using well water that significantly decreases the risk when analyzed using multivariate analysis (Yang et al., 2008; Yang et al., 2006b). However, in Hokkaido, the use of well water was a significant risk factor and the use of tap water significantly decreased the risk of an individual having $\mathrm{AE}$ (Yamamoto et al., 2001). The obvious differences between the results of these studies in different endemic countries of Asia may be explained by the relative level of development in rural China and Japan at the beginning of the 21st century, tap water being safer than well water, itself safer than stream or ponds/lakes. This also means that, although the role of water as carrier of infective parasite eggs makes sense, one cannot exclude that this factor may be the proxy of another causal variable such as general hygienic conditions as well.

Only few studies have addressed environmental contamination with Echinococcus eggs beyond carnivore fecal samples. A pioneer approach, which was not further exploited in other studies, was based on Echinococcus 4E5 monoclonal antibodies for the detection of $E$. granulosus eggs in environmental contamination sites in settlements in Turkana (Kenya) (Craig et al., 1986). Samples from inside Turkana huts (akai) and from water samples from open waterholes used by the people and their livestock, reacted positively with the Echinococcus 4E5 monoclonal antibody (Craig et al., 1988). Molecular techniques have been used in more recent studies: Shaikenov et al. investigated 120 soil samples using a modified flotation method followed by PCR identification of E. granulosus eggs and identified $4 E$. granulosus-positive samples among the 21 samples which contained taeniid eggs (Shaikenov et al., 2004); Szostakowska et al. analyzed soil samples for the presence of E. multilocularis using first sedimentation/flotation and then DNA isolation by repeated freezing-thawing followed by a semi-nested PCRs; the results were indicative for $E$. multilocularis in 7/62 soil samples; 3 were confirmed by sequencing (Szostakowska et al., 2014). The same team looked for the presence of E. multilocularis DNA in fruits, 
vegetables, and mushrooms intended for consumption in Poland (Lass et al., 2015). Samples contained at least 100 eggs of the tapeworm; nested PCR assay based on the mitochondrial 12S ribosomal RNA (rRNA) gene detected parasite DNA in $23.3 \%$ of the samples; sequencing confirmed the presence of $E$. multilocularis. The results seem to clearly demonstrate that fruit and vegetables collected in forests, plantations, and kitchen gardens may be a direct source of human infections; however, such results should be reproduced in other endemic areas to become really convincing; in addition, these data provide no clue about the origin of egg presence on the foods, either direct contact with infected fox/dog feces, or secondary infection through irrigation water or spreading of sludge from water treatment plants. Using an adapted sieving system combined with DNA identification it was possible to isolate and identify taeniid eggs ( $E$. granulosus s.l., T. saginata, T. taeniaeformis, T. hydatigena and T. ovis) from the washing water of fruit and vegetables aimed at feeding primates in the zoo of Basel and produced in northeastern Switzerland and in different European countries (Federer et al., 2016). Although DNA of E. multilocularis was not found specifically in this study, the detection of other fox taeniids strongly suggested that $\mathrm{AE}$ in primates of this zoo might be due to vegetables and fruit fed to these primates. In their recent review, Conraths and Deplazes (Conraths and Deplazes, 2015) reported that they were able to detect E. multilocularis, T. saginata and Diphyllobothrium latum eggs from large volumes of purified wastewater of a water purification station before the last step of filtration. This is a major step towards further studies which could address the persistence and survival of Echinococcus spp. eggs during the various stages of sanitation and wastewater treatment. To our knowledge, there are no data from Chinese research teams or public health/veterinary control institutions regarding the presence of Echinococcus spp. in water or any sources related to water treatment (sewage, biosolids /sludge from water treatment plants...), in international scientific publications but also in scientific publications in Chinese, or in grey literature produced by governmental or nongovernmental institutions.

\subsection{Survival (Persistence) in the Environment}

\subsubsection{Methods for assessing survival}

Survival of Echinococcus spp. eggs in environment may only be assessed by infection of susceptible experimental rodents, voles, gerbils, or susceptible laboratory mice, using eggs maintained in controlled environmental conditions, either in the laboratory or in nature, under measured climatic conditions (Eckert et al., 2001a; Eckert et al., 2001b; Thompson and McManus, 2001). However, results obtained with this method obviously depend on the number and susceptibility of the rodent used for the experiments. A sensitive in vivo method using sodium hypochlorite resistant oncospheres for subcutaneous inoculation of mice was recently developed to determine the viability of E. multilocularis eggs and to establish suitable conditions (optimal temperature, exposure time and humidity) for their inactivation (Federer et al., 2015).

\subsubsection{Data on persistence of the eggs}

Under natural climatic conditions of southern Germany, the maximal survival time of E. multilocularis eggs was 8 months in an experiment performed in autumn and winter, and almost 3 months in summer; however, relative resistance of the eggs to the high temperatures of summer could be due to the environmental conditions (e.g. shadow, or exposure to the North which may protect the eggs from heating and desiccation); and the viability test was performed on a rather low number of common voles (Microtus arvalis) (Veit et al., 1995).

Under lab conditions, at $45^{\circ} \mathrm{C}$ and $85-95 \%$ relative humidity the infectivity was lost after 3 hours as well as after 4 hours exposure to $43^{\circ} \mathrm{C}$ suspended in water. Exposure to at $43^{\circ} \mathrm{C}$ with $15 \%$ relative humidity resulted in a total loss of infectivity within 2 hours.

At $25^{\circ} \mathrm{C}$ exposure to $27 \%$ relative humidity resulted in a total loss of infectivity within 48 hours.

Temperatures of $4^{\circ} \mathrm{C}$ and of $-18^{\circ} \mathrm{C}$ were well tolerated (478 days and 240 days survival, respectively), whereas exposure to $-83^{\circ} \mathrm{C}$ and to $-196^{\circ} \mathrm{C}$ quickly killed off the eggs (within 48 hours and 20 hours respectively) (Veit et al., 1995). In lab experiments using the methodology recently described by (Federer et al., 2015), eggs exposed to increasing temperatures were more resistant to heat if suspended in water as compared to eggs exposed on a filter paper at $70 \%$ relative humidity; eggs suspended in water were infectious after heat exposure at $65^{\circ} \mathrm{C}$ for up to $120 \mathrm{~min}$; however, no echinococcosis developed after treatment of the eggs at $65^{\circ} \mathrm{C}$ for $180 \mathrm{~min}$ or at 70,75 and $80^{\circ} \mathrm{C}$ for $7.5,15$ or 30 min (Federer et al., 2015).

\subsection{Reducing Environmental Contamination By Sanitation Measures}

There are no systematic studies regarding reduction of Echinococcus spp. eggs by sanitation technologies. However, the eggs are found in soil and animal excreta thus several experiments on the resistance/susceptibility of Echinococcus spp. eggs to various physical and chemical treatments may provide some indication on the efficacy of the different procedures used for water sanitation. As described above, loss of infectivity by the eggs of $E$. multilocularis was positively related to dryness and higher temperature (Federer et al., 2015; Veit et al., 1995). Currently, in specialized labs working on Echinococcus spp. eggs, the usual methods of inactivation without destruction of the samples under study (e.g. carnivore intestines) is freezing at $-70 /-80^{\circ} \mathrm{C}$ during at least one week; freezing at $-18-20^{\circ} \mathrm{C}$ (family freezers) is not sufficient to inactivate Echinococcus spp. eggs. Conversely, boiling in water is totally efficient to inactivate Echinococcus spp. eggs (Eckert et al., 2001b). It has been recommended that infective material should be examined over sinks, in which an immersion heater can be placed to enable material to be boiled in water before it is passed into a sewerage system (Gemmell, 1968). In situations where the intestines of definitive hosts have to be examined, to prevent 
contamination of wastewater, this should be done on metal trays or on disposable plastic foils. Following examination, the tray and all instruments should be sterilized, ideally by steam sterilization in an autoclave. Plastic sheets, carcasses or organ material can be autoclaved or incinerated (Eckert et al., 2001b). After purgation of dogs with arecoline and/or after PZQ treatment or maintenance of infected carnivores in confined areas, such as kennels, large numbers of infective Echinococcus eggs may contaminate the environment. Therefore, purgation or treatment should whenever possible - be carried out in rooms or confined sites with a concrete floor, which can easily be cleaned and disinfected. Alternatively, sites of purgation/treatment may be covered with a plastic sheet, which can be incinerated. If soil has been contaminated with Echinococcus eggs, the surface layer (approximately $1 \mathrm{~cm}-2 \mathrm{~cm}$ ) should be removed, and the ground thoroughly burned with a firelamp or a small flame-thrower. It should be considered that, although high temperatures are generated by these devices, decontamination may not be complete because of rapid decrease of temperature after contact of the flame with soil, especially moist soil (Gemmell, 1968).

\subsection{Excreta and wastewater treatment}

There are no specific studies regarding Echinococcus spp removal by a whole array of wastewater treatment; however, it may be reminded that Echinococcus eggs are not released by humans feces but only by the feces of carnivore hosts.

\subsubsection{Composting}

Based on experiments with Ascaris eggs, it can be assumed that the eggs of Taenia and Echinococcus are killed in compost after exposure for at least $30 \mathrm{~min}$ to temperatures of $+65^{\circ} \mathrm{C}$ or higher, generated by heating or fermentation processes (Eckert, 2000).

\subsubsection{Sewage treatment}

Most sewage treatment processes (for example sedimentation) do not totally eliminate taeniid eggs (Eckert, 2000). It may be reminded that the diameter of Echinococcus spp. eggs ranges between 25 and $30 \mu \mathrm{m}$, and will thus be retained by filters/sieves under $20 \mu \mathrm{m}$.

\subsubsection{Biosolids andsludge treatment}

Based on experiments with Ascaris eggs, it can be assumed that the eggs of Taenia spp. and Echinococcus spp. are killed in sewage sludge if temperatures reach the higher level (see the persistence section (Eckert et al., 2001b). However there are no specific studies to provide evidence for Echinococcus spp. egg killing in sewage sludge.

\subsection{Disinfection}

There are no specific studies regarding Echinococcus spp. eggs.
3.2.1 Chemical disinfection (chlorine, alcohol and phenols)

Only sodium hypochlorite solution $(\mathrm{NaOCl})$ at a minimum concentration of $3.75 \%$ in water disrupts the embryophores of Echinococcus eggs and damages the majority of the oncospheres within a few minutes (Craig and MacPherson, 1988). However, the effect of this disinfectant is variable and depends on the actual chlorine concentration, on temperature and the depth of penetration; it does not penetrate easily into organic materials. This may have been the reason why exposure of E. multilocularis eggs to a household disinfectant containing $\mathrm{NaOCl}$ with 'under $5 \%$ free chlorine' did not kill all eggs after 5 min (Veit et al., 1995). This is also strongly suggested by the results of the sodium hypochlorite resistance test developed by Federer et al. (Federer et al., 2015).

Eggs of E. granulosus retained viability in ethanol (50\%, $70 \%, 95 \%$ ) after $5 \mathrm{~min}$ to $60 \mathrm{~min}$ exposure (Laws, 1967; Meymarian and Schwabe, 1962; Parnell, 1965), but only a few survived in glutaraldehyde (5\% and 10\%) (Pérez-Esandi et al., 1974). Studies performed in the 1950s-1960s showed that $4 \%-10 \%$ formalin (used as fixatives) were not ovicidal (Hercus et al., 1962), which is confirmed by the observation that eggs of $T$. pisiformis (very similar in terms of structure) survived for 3 weeks in $10 \%$ formalin (Eckert et al., 2001b).

Most of the commercial disinfectants with activity against viruses and bacteria are ineffective against Echinococcus eggs. The efficacy of 10 commercial disinfectants, containing phenol derivatives, aldehydes, ethanol phosphoric acid and other substances, was tested against $E$. multilocularis eggs. None of these disinfectants used in the recommended concentrations and application times, killed the eggs, as well as exposure for $24 \mathrm{~h}$ to low concentrations of ethanol, as shown in vitro and by peroral inoculation to common voles (Veit et al., 1995).

\subsubsection{Ultraviolet}

The inhibitory effect of UV lamps at different exposure durations on E. multilocularis eggs was determined by the reduction in the larval cyst establishment and by the delay of larval development (Lagapa et al., 2001). The UVC lamp (narrow peak at $254 \mathrm{~nm}$ ) was found to be the most effective lamp at an exposure duration of more than $2,430 \mathrm{~s}(2,430$ $\mathrm{mJ} / \mathrm{cm} 2$ ), attaining $100 \%$ reduction. Also, shorter exposure durations produced a significant effect on the development of irradiated eggs in a greater percentage of small cysts (> $1 \mathrm{~mm}$ ) among the metacestodes. Irradiation delayed the development of some cysts, as observed in histopathological sections. UVA and UVB lamps were not able to attain $100 \%$ reduction. It is concluded that the UVC lamp can be used as a tool in sterilizing taeniid eggs and is thus a promising method to control echinococcosis, although it may require a higher intensity of exposure.

\subsubsection{Irradiation}

For inactivation of taeniid eggs irradiation doses higher 
than 40 krad are apparently required: after infection of laboratory rodents with eggs of Taenia taeniaeformis irradiated at $60 \mathrm{krad}$ metacestodes did not develop (Dow et al., 1962).The infectivity of E. granulosus eggs after irradiation with doses of 10,20 and $30 \mathrm{krad}(=100,200$ and 300 Gray) was diminished, but not lost (Williams and Colli, 1972). Echinococcus multilocularis eggs irradiated with a dose of $40 \mathrm{krad}$ triggered specific antibody production but metacestodes did not develop (Veit et al., 1995). 


\section{References}

Afonso, E., Knapp, J., Tête, N., Umhang, G., Rieffel, D., van Kesteren, F. et al. (2015). Echinococcus multilocularis in Kyrgyzstan: similarity in the Asian EmsB genotypic profiles from village populations of Eastern mole voles (Ellobius tancrei) and dogs in the Alay valley. Journal of Helminthology. 89, pp. 664-670. doi: 10.1017/S0022149X15000474.

Ahmadi, N.A. and Meshkehkar, M. (2011). An abattoir-based study on the prevalence and economic losses due to cystic echinococcosis in slaughtered herbivores in Ahwaz, south-western Iran. Journal of Helminthology. 85, pp. 33-39. doi: 10.1017/S0022149X10000234.

Al-Sabi, M.Nafi Solai, Kapel, C.M.O., Webster, P. and Deplazes, P. (2008). Reduced egg production of Echinococcus multilocularis in experimentally infected and re-infected red foxes (Vulpes vulpes). Veterinary Parasitology. 155, pp. 59-66. doi: 10.1016/j.vetpar.2008.04.010.

Allan, J.C. and Craig, P.S. (2006). Coproantigens in taeniasis and echinococcosis. Parasitology International. 55 Suppl, pp. S75-80. doi: 10.1016/j.parint.2005.11.010.

Ambregna, S., Koch, S., Sulz, M.C., Grüner, B., Öztürk, S., Chevaux, J.-B. et al. (2017). A European survey of perendoscopic treatment of biliary complications in patients with alveolar echinococcosis. Expert Review of Anti-infective Therapy. 15, pp. 79-88. doi: 10.1080/14787210.2017.1252260.

Ammann, R.W. (2000). Chemotherapy alone or as adjuvant treatment to surgery for alveolar and cystic echinococcosis. Der Chirurg; Zeitschrift Für Alle Gebiete Der Operativen Medizen. 71, pp. 9-15.

Ammann, R.W., Hoffmann, A.F. and Eckert, J. (1999). Swiss study of chemotherapy of alveolar echinococcosis-review of a 20-year clinical research project. Schweizerische Medizinische Wochenschrift. 129, pp. 323-332.

Ayifuhan, A., Tuerganaili, A., Jun, C., Ying-Mei, S., Xiang-Wei, L. and Hao, W. (2012). Surgical treatment for hepatic alveolar echinococcosis: report of 50 cases. Hepato-Gastroenterology. 59, pp. 790-793. doi: 10.5754/hge10545.

Böttcher, D., Bangoura, B., Schmäschke, R., Müller, K., Fischer, S., Vobis, V. et al. (2013). Diagnostics and epidemiology of alveolar echinococcosis in slaughtered pigs from large-scale husbandries in Germany. Parasitology Research. 112, pp. 629-636. doi: 10.1007/s00436-012-3177-2.

Baldock, F.C., Thompson, R.C., Kumaratilake, L.M. and Shield, J. (1985). Echinococcus granulosus in farm dogs and dingoes in south eastern Queensland. Australian Veterinary Journal. 62, pp. 335-337.

Barnes, T.S., Deplazes, P., Gottstein, B., Jenkins, D.J., Mathis, A., Siles-Lucas, M. et al. (2012). Challenges for diagnosis and control of cystic hydatid disease. Acta Tropica. 123, pp. 1-7. doi: 10.1016/j.actatropica.2012.02.066.

Bart, J.M., Knapp, J., Gottstein, B., El-Garch, F., Giraudoux, P., Glowatzki, M.L. et al. (2006). EmsB, a tandem repeated multi-loci microsatellite, new tool to investigate the genetic diversity of Echinococcus multilocularis. Infection, Genetics and Evolution: Journal of Molecular Epidemiology and Evolutionary Genetics in Infectious Diseases. 6, pp. 390-400. doi: 10.1016/j.meegid.2006.01.006.

Benner, C., Carabin, H., Sánchez-Serrano, L.P., Budke, C.M. and Carmena, D. (2010). Analysis of the economic impact of cystic echinococcosis in Spain. Bulletin of the World Health Organization. 88, pp. 49-57. doi: 10.2471/BLT.09.066795.

Boubaker, G., Macchiaroli, N., Prada, L., Cucher, M.A., Rosenzvit, M.C., Ziadinov, I. et al. (2013). A multiplex PCR for the simultaneous detection and genotyping of the Echinococcus granulosus complex. PLoS neglected tropical diseases. 7, pp. e2017. doi: 10.1371/journal.pntd.0002017.

Bresson-Hadni, S., Delabrousse, E., Blagosklonov, O., Bartholomot, B., Koch, S., Miguet, J.-.P. et al. (2006). Imaging aspects and non-surgical interventional treatment in human alveolar echinococcosis. International Journal for Parasitology. 55 Suppl, pp. S267-272. doi: 10.1016/j.parint.2005.11.053.

Bresson-Hadni, S., Miguet, J.P., Mantion, G.A. and Vuitton, D.A. (2007). Echinococcosis of the liver. Textbook of 
Hepatology: From Basic Science to Clinical Practice. 3rd ed. Blackwell Publishing. Oxford. pp. 1047-1057.

Bresson-Hadni, S., Koch, S., Beurton, I., Vuitton, D.A., Bartholomot, B., Hrusovsky, S. et al. (1999). Primary disease recurrence after liver transplantation for alveolar echinococcosis: long-term evaluation in 15 patients. Hepatology (Baltimore, Md.). 30, pp. 857-864. doi: 10.1002/hep.510300426.

Bresson-Hadni, S., Vuitton, D.A., Bartholomot, B., Heyd, B., Godart, D., Meyer, J.P. et al. (2000). A twenty-year history of alveolar echinococcosis: analysis of a series of 117 patients from eastern France. European Journal of Gastroenterology and Hepatology. 12, pp. 327-336.

Bresson-Hadni, S., Delabrousse, E., Blagosklonov, O., Bartholomot, B., Koch, S., Miguet, J.-.P. et al. (2006). Imaging aspects and non-surgical interventional treatment in human alveolar echinococcosis. Parasitology International. 55 Suppl, pp. S267-272. doi: 10.1016/j.parint.2005.11.053.

Bretagne, S., Guillou, J.P., Morand, M. and Houin, R. (1993). Detection of Echinococcus multilocularis DNA in fox faeces using DNA amplification. Parasitology. 106(Pt 2), pp. 193-199.

Brunetti, E., Kern, P., Vuitton, D.Angèle and WHO-IWGE, W.Panel for (2010). Expert consensus for the diagnosis and treatment of cystic and alveolar echinococcosis in humans. Acta Tropica. 114, pp. 1-16. doi: $10.1016 /$ j.actatropica.2009.11.001.

Budke, C.M., Deplazes, P. and Torgerson, P.R. (2006). Global socioeconomic impact of cystic echinococcosis. Emerging Infectious Diseases. 12, pp. 296-303. doi: 10.3201/eid1202.050499.

Budke, C.M., Jiamin, Q., Craig, P.S. and Torgerson, P.R. (2005). Modeling the transmission of Echinococcus granulosus and Echinococcus multilocularis in dogs for a high endemic region of the Tibetan plateau. International Journal for Parasitology. 35, pp. 163-170. doi: 10.1016/j.ijpara.2004.10.026.

Budke, C.M., Jiamin, Q., Qian, W. and Torgerson, P.R. (2005). Economic effects of echinococcosis in a disease-endemic region of the Tibetan Plateau. The American Journal of Tropical Medicine and Hygiene. 73, pp. 2-10.

Budke, C.M., Jiamin, Q., Zinsstag, J., Qian, W. and Torgerson, P.R. (2004). Use of disability adjusted life years in the estimation of the disease burden of echinococcosis for a high endemic region of the Tibetan plateau. The American Journal of Tropical Medicine and Hygiene. 71, pp. 56-64.

Buttenschoen, K., Buttenschoen, D.Carli, Gruener, B., Kern, P., Beger, H.G., Henne-Bruns, D. et al. (2009). Long-term experience on surgical treatment of alveolar echinococcosis. Langenbeck's Archives of Surgery / Deutsche Gesellschaft Für Chirurgie. 394, pp. 689-698. doi: 10.1007/s00423-008-0392-5.

Caoduro, C., Porot, C., Vuitton, D.A., Bresson-Hadni, S., Grenouillet, F., Richou, C. et al. (2013). The role of delayed 18FFDG PET imaging in the follow-up of patients with alveolar echinococcosis. Journal of Nuclear Medicine: Official Publication, Society of Nuclear Medicine. 54, pp. 358-363. doi: 10.2967/jnumed.112.109942.

Capdevielle, P. (1984). [Hepatic hydatidosis associated with a probable immune deficiency]. Presse Médicale (Paris, France: 1983). 13, pp. 1965.

Carabin, H., Budke, C.M., Cowan, L.D., A. Willingham, L. and Torgerson, P.R. (2005). Methods for assessing the burden of parasitic zoonoses: echinococcosis and cysticercosis. Trends in Parasitology. 21, pp. 327-333. doi: 10.1016/j.pt.2005.05.009.

Carabin, H., Torgerson, P.R., Budke, C., Cowan, L.D., Nash, T., Willingham, A.L. et al. (2004). Assessing the burden of Taenia solium cysticercosis and echinococcosis. Veterinary Parasitology. 125, pp. 183-202.

Catalano, S., Lejeune, M., Liccioli, S., Verocai, G.G., Gesy, K.M., Jenkins, E.J. et al. (2012). Echinococcus multilocularis in urban coyotes, Alberta, Canada. Emerging Infectious Diseases. 18, pp. 1625-1628. doi: 10.3201/eid.1810.120119.

Charles, S.D., Altreuther, G., Reinemeyer, C.R., Buch, J., Settje, T., Cruthers, L. et al. (2005). Evaluation of the efficacy of emodepside+praziquantel topical solution against cestode (Dipylidium caninum, Taenia taeniaeformis, and Echinococcus 
multilocularis) infections in cats. Parasitology Research. 97 Supp 1, pp. S33-40. doi: 10.1007/s00436-005-1442-3.

Chauchet, A., Grenouillet, F., Knapp, J., Richou, C., Delabrousse, E., Dentan, C. et al. (2014). Increased incidence and characteristics of alveolar echinococcosis in patients with immunosuppression-associated conditions. Clinical Infectious Diseases: An Official Publication of the Infectious Diseases Society of America. 59, pp. 1095-1104. doi: 10.1093/cid/ciu520.

Chaâbane-Banaoues, R., Oudni-M'rad, M., M'rad, S., Amani, H., Mezhoud, H. and Babba, H. (2016). A novel PCR-RFLP assay for molecular characterization of Echinococcus granulosus sensu lato and closely related species in developing countries. Parasitology Research. 115, pp. 3817- 3824. doi: 10.1007/s00436-016-5143-x.

China, T.Central Pe (2014). National Chinese Program on Echinococcosis Prevention and Control, 2010-2015.

Christiansen, E.F., Himsworth, C.G., Hill, J.E. and Haulena, M. (2015). Infection of a Goeldi's monkey (Callimico Goeldii) with a European strain of Echinococcus multilocularis in a Canadian institution. Journal of Zoo and Wildlife Medicine. 46, pp. 378-381. doi: 10.1638/2014-0123R1.1.

Coeurdassier, M., Riols, R., Decors, A., Mionnet, A., David, F., Quintaine, T. et al. (2014). Unintentional wildlife poisoning and proposals for sustainable management of rodents. Conservation Biology: The Journal of the Society for Conservation Biology. 28, pp. 315-321. doi: 10.1111/cobi.12230.

Collins, G.H. and Pope, S.E. (1990). Cysticercus bovis in cattle in New South Wales. Australian Veterinary Journal. 67, pp. 228-229.

Combes, B., Comte, S., Raton, V., Raoul, F., Boué, F., Umhang, G. et al. (2012). Westward spread of Echinococcus multilocularis in foxes, France, 2005-2010. Emerging Infectious Diseases. 18, pp. 2059-2062. doi: 10.3201/eid1812.120219.

Comte, S., Raton, V., Raoul, F., Hegglin, D., Giraudoux, P., Deplazes, P. et al. (2013). Fox baiting against Echinococcus multilocularis: contrasted achievements among two medium size cities. Preventive Veterinary Medicine. 111, pp. 147-155. doi: 10.1016/j.prevetmed.2013.03.016.

Conraths, F.J. and Deplazes, P. (2015). Echinococcus multilocularis: Epidemiology, surveillance and state-of-the-art diagnostics from a veterinary public health perspective. Veterinary Parasitology. 213, pp. 149-161. doi: 10.1016/j.vetpar.2015.07.027.

Craig, P.S., Deshan, L., MacPherson, C.N., Dazhong, S., Reynolds, D., Barnish, G. et al. (1992). A large focus of alveolar echinococcosis in central China. Lancet (London, England). 340, pp. 826-831.

Craig, P.S., Giraudoux, P., Shi, D., Bartholomot, B., Barnish, G., Delattre, P. et al. (2000). An epidemiological and ecological study of human alveolar echinococcosis transmission in south Gansu, China. Acta Tropica. 77, pp. 167-177.

Craig, P.S. and MacPherson, C.N. (1988). Sodium hypochlorite as an ovicide for Echinococcus. Annals of Tropical Medicine and Parasitology. 82, pp. 211-213.

Craig, P.S., MacPherson, C.N. and Nelson, G.S. (1986). The identification of eggs of Echinococcus by immunofluorescence using a specific anti-oncospheral monoclonal antibody. The American Journal of Tropical Medicine and Hygiene. 35, pp. 152-158.

Craig, P.S., McManus, D.P., Lightowlers, M.W., Chabalgoity, J.A., Garcia, H.H., Gavidia, C.M. et al. (2007). Prevention and control of cystic echinococcosis. The Lancet. Infectious Diseases. 7, pp. 385-394. doi: 10.1016/S1473-3099(07)70134-2.

D'Alessandro, A., Rausch, R.L., Morales, G.A., Collet, S. and Angel, D. (1981). Echinococcus infections in Colombian animals. Am. J. Trop. Med. Hyg. 30, pp. 1263.

Dang, Z., Yagi, K., Oku, Y., Kouguchi, H., Kajino, K., Matsumoto, J. et al. (2012). A pilot study on developing mucosal vaccine against alveolar echinococcosis (AE) using recombinant tetraspanin 3: Vaccine efficacy and immunology. PLoS neglected tropical diseases. 6, pp. e1570. doi: 10.1371/journal.pntd.0001570. 
Davidson, R.K., Romig, T., Jenkins, E., Tryland, M. and Robertson, L.J. (2012). The impact of globalisation on the distribution of Echinococcus multilocularis. Trends in Parasitology. 28, pp. 239-247. doi: 10.1016/j.pt.2012.03.004.

Davidson, W.R., Appel, M.J., Doster, G.L., Baker, O.E. and Brown, J.F. (1992). Diseases and parasites of red foxes, gray foxes, and coyotes from commercial sources selling to fox-chasing enclosures. Journal of Wildlife Diseases. 28, pp. 581-589. doi: 10.7589/0090-3558-28.4.581.

Delattre, P. and Giraudoux, P. (2005). Le contrôle des rongeurs non commensaux: impasse du tout chimique et perspectives de lutte intégrée. Enjeux phytosanitaires pour l'agriculture et l'environnement : pesticides et biopesticides, agriculture durable. Tec. et Doc. ed. Regnault-Roger, C., Fabre, G., Philogène, B. Cachan, France.

Delattre, P., Giraudoux, P. and Quéré, J.P. (1990). Conséquences épidémiologiques de la réceptivité d'un nouvel hôte intermédiaire du Ténia multiloculaire (Echinococcus multilocularis) et de la localisation spatio-temporelle des rongeurs infestés. Comptes Rendus de l'Académie des Sciences (Paris). 310, pp. 339-344.

Delattre, P., Pascal, M., Le Pesteur, M.H., Giraudoux, P. and Damange, J.P. (1988). Caractéristiques écologiques et épidémiologiques de l'Echinococcus multilocularis au cours d'un cycle complet des populations d'un hôte intermédiaire (Microtus arvalis). Canadian Journal of Zoology. 66, pp. 2740-2750.

Delattre, P., Giraudoux, P., Baudry, J., Truchetet, D., Musard, P., Toussaint, M. et al. (1992). Land use patterns and types of common vole (Microtus arvalis) population kinetics. Agriculture, Agrosystems and the Environment. 39, pp. 153-169.

Dentan, C., Mazet, R., Gilson, M., Marchou-Lopez, S. and Gaudin, P. (2012). Rheumatoid arthritis, alveolar echinococcosis, and rituximab: a case report. Joint, Bone, Spine: Revue Du Rhumatisme. 79, pp. 325-327. doi: 10.1016/j.jbspin.2011.10.014.

Deplazes, P., Alther, P., Tanner, I., Thompson, R.C. and Eckert, J. (1999). Echinococcus multilocularis coproantigen detection by enzyme-linked immunosorbent assay in fox, dog, and cat populations. The Journal of Parasitology. 85, pp. 115-121.

Deplazes, P. and Eckert, J. (2001). Veterinary aspects of alveolar echinococcosis-a zoonosis of public health significance. Veterinary Parasitology. 98, pp. 65-87.

Deplazes, P., Rinaldi, L., Rojas, C.A.Alvarez, Torgerson, P., Harandi, M., Romig, T. et al. (2017). Global distribution of alveolar and cystic echinococcosis. Advances in Parasitology.

Deplazes, P., Hegglin, D., Gloor, S. and Romig, T. (2004). Wilderness in the city: the urbanization of Echinococcus multilocularis. Trends in Parasitology. 20, pp. 77-84.

Devleesschauwer, B., Ale, A., Torgerson, P., Praet, N., de Noordhout, C.Maertens, Pandey, B.Dev et al. (2014). The burden of parasitic zoonoses in Nepal: a systematic review. PLoS neglected tropical diseases. 8, pp. e2634. doi: 10.1371/journal.pntd.0002634.

Dinkel, A., von Nickisch-Rosenegk, M., Bilger, B., Merli, M., Lucius, R. and Romig, T. (1998). Detection of Echinococcus multilocularis in the definitive host: coprodiagnosis by PCR as an alternative to necropsy. Journal of Clinical Microbiology. 36, pp. 1871-1876.

Dinkel, A., Kern, S., Brinker, A., Oehme, R., Vaniscotte, A., Giraudoux, P. et al. (2011). A real-time multiplex-nested PCR system for coprological diagnosis of Echinococcus multilocularis and host species. Journal of Parasitology Research. 109, pp. 493-498. doi: 10.1007/s00436-011-2272-0.

Dow, G., Jarrett, W.F., Jennings, F.W., McINTYRE, W.I. and Mulligan, W. (1962). The production of immunity to Cysticercus fasciolaris, using x-irradiated oncospheres. American Journal of Veterinary Research. 23, pp. 146-149.

Dudarev, A.A., Dorofeyev, V.M., Dushkina, E.V., Alloyarov, P.R., Chupakhin, V.S., Sladkova, Y.N. et al. (2013). Food and water security issues in Russia III: food- and waterborne diseases in the Russian Arctic, Siberia and the Far East, 2000-2011. International Journal of Circumpolar Health. 72, pp. 21856. doi: 10.3402/ijch.v72i0.21856. 
Echinococcosis, WHO.Informal W. (1996). Guidelines for treatment of cystic and alveolar echinococcosis in humans. Bulletin of the World Health Organization. 74, pp. 231-242.

Eckert, J. (2000). Parasite Stages as an Environmental Health Problem. Veterinarian Medical Parasitology.

Eckert, J. and Deplazes, P. (2004). Biological, epidemiological, and clinical aspects of echinococcosis, a zoonosis of increasing concern. Clinical Microbiology Reviews. 17, pp. 107-135.

Eckert, J., Deplazes, P., Craig, P.S., Gemmell, M.A., Gottstein, B., Heath, D. et al. (2001). Echinococcosis in animals: clinical aspects, diagnosis and treatment. WHO/OIE Manual on Echinococcosis in Humans and Animals: a Public Health Problem of Global Concern. World Organization for Animal Health (OIE) ed. Eckert J, Gemmell MA, Meslin FX, Pawlowski ZS. Paris. pp. 72-99.

Eckert, J., Gottstein, B., Heath, D. and Liu, F.J. (2001). Prevention of echinococcosis in humans and safety precautions. WHO/OIE Manual on Echinococcosis in Humans and Animals: a Public Health Problem of Global Concern. World Organization for Animal Health (OIE) ed. Eckert J, Gemmell MA, Meslin FX, Pawlowski ZS. Paris. pp. 258-267.

Eckert, J., Rausch, R.L., Gemmell, M.A., Giraudoux, P., Kamiya, M., Liu, F.J. et al. (2001). Epidemiology of Echinococcus multilocularis, Echinococcus vogeli and Echinococcus oligarthrus. WHO/OIE Manual on Echinococcosis in Humans and Animals: a Public Health Problem of Global Concern. World Organization for Animal Health (OIE) ed. Eckert J, Gemmell MA, Meslin FX, Pawlowski ZS. Paris. pp. 164-194.

Eckert, J., Schantz, P.M., Gasser, R.B., Torgerson, P.R., Bessonov, A.S., Movsessian, S.O. et al. (2001). Geographic distribution and prevalence. WHO/OIE Manual on Echinococcosis in Humans and Animals: a Public Health Problem of Global Concern. World Organization for Animal Health (OIE) ed. Eckert J, Gemmell MA, Meslin FX, Pawlowski ZS. Paris. pp. 101-143.

Eckert, J. (2003). Predictive values and quality control of techniques for the diagnosis of Echinococcus multilocularis in definitive hosts. Acta Tropica. 85, pp. 157-163.

Eiermann, T.H., Bettens, F., Tiberghien, P., Schmitz, K., Beurton, I., Bresson-Hadni, S. et al. (1998). HLA and alveolar echinococcosis. Tissue Antigens. 52, pp. 124-129.

Erayman, I., Kalkan, E., Erdi, F., Kerimoglu, U. and Esen, H. (2011). Primary spinal hydatid cyst in a patient with acquired immunodeficiency syndrome. European Spine Journal. 20 Suppl 2, pp. S235-238. doi: 10.1007/s00586-010-1614-4.

Fay, F.H. (1973). The ecology of Echinococcus multiocularis Leuckart, 1863, (Cestoda: Taeniidae) on St. Lawrence Island, Alaska. I. Background and rationale. Annales De Parasitologie Humaine Et Comparée. 48, pp. 523-542.

Federer, K., Armua-Fernandez, M.T., Hoby, S., Wenker, C. and Deplazes, P. (2015). In vivo viability of Echinococcus multilocularis eggs in a rodent model after different thermo-treatments. Experimental Parasitology. 154, pp. 14-19. doi: 10.1016/j.exppara.2015.03.016.

Federer, K., Armua-Fernandez, M.T., Gori, F., Hoby, S., Wenker, C. and Deplazes, P. (2016). Detection of taeniid (Taenia spp., Echinococcus spp.) eggs contaminating vegetables and fruits sold in European markets and the risk for metacestode infections in captive primates. International Journal for Parasitology: Parasites and Wildlife. 5, pp. 249-253. doi: 10.1016/j.jppaw.2016.07.002.

Frank, W. (1989). Survival of Echinococcus multilocularis eggs in the environment and potential modes of transmission. World Health Organization Informal Consultation on Alveolar Echinococcosis. WHO document VPH/Echin.Res/WP/89. World Health Organization ed. pp. 1-5.

Frei, P., Misselwitz, B., Prakash, M.K., Schoepfer, A.M., Vavricka, B.M.Prinz, Müllhaupt, B. et al. (2014). Late biliary complications in human alveolar echinococcosis are associated with high mortality. World Journal of Gastroenterology. 20, pp. 5881-5888. doi: 10.3748/wjg.v20.i19.5881.

Frider, B., Larrieu, E. and Odriozola, M. (1999). Long-term outcome of asymptomatic liver hydatidosis. Journal of Hepatology. 30, pp. 228-231.

Gauci, C., Heath, D., Chow, C. and Lightowlers, M.W. (2005). Hydatid disease: vaccinology and development of the EG95 
recombinant vaccine. Expert Review of Vaccines. 4, pp. 103-112. doi: 10.1586/14760584.4.1.103.

Gaultier, J.-.B., Hot, A., Mauservey, C., Dumortier, J., Coppéré, B. and Ninet, J. (2009). [Granulomatous liver disease as the presenting feature of alveolar echinococcosis in an hepatitis C infected cardiac transplant patient]. La Revue De Médecine Interne / Fondée. Par La Société Nationale Francaise De Médecine Interne. 30, pp. 812-815. doi: 10.1016/j.revmed.2008.11.007.

Gemmell, M.A. (1977). Taeniidae: modification to the life span of the egg and the regulation of tapeworm populations. Experimental Parasitology. 41, pp. 314-328.

Gemmell, M.A. (1968). Safe handling of infected definitive hosts and eggs of Echinococcus spp. Bulletin of the World Health Organization. 39, pp. 122-125.

Gemmell, M.A., Johnstone, P.D. and Oudemans, G. (1977). The effect of praziquantel on Echinococcus granulosus, Taenia hydatigena and Taenia ovis infections in dogs. Research in Veterinary Science. 23, pp. 121-123.

Gemmell, M.A., Lawson, J.R. and Roberts, M.G. (1987). Towards global control of cystic and alveolar hydatid diseases. Parasitology Today (Personal Ed.). 3, pp. 144-151.

Gemmell, M.A., Lawson, J.R. and Roberts, M.G. (1986). Population dynamics in echinococcosis and cysticercosis: biological parameters of Echinococcus granulosus in dogs and sheep. Parasitology. 92 ( Pt 3), pp. 599-620.

Gemmell, M.A. (1997). Quantifying the transmission dynamics of the family Taeniidae with particular reference to Echinococcus spp.: an update. Compendium of cystic echinococcosis in Africa and in the Middle Eastern Countries with special reference to Morocco. Brigham Young University, Print Services ed. Andersen FL,Ouhelli H, Kachani M. Provo, Utah. pp. 54-73.

Gemmell, M.A., Roberts, M.G., Beard, T.C., S Diaz, C.,., and Nonnemaker, J.M. (2001). Formulating effective and costeffective policies in the planning phase for permanent control of Echinococcus granulosus. WHO/OIE Manual on Echinococcosis in Humans and Animals: a Public Health Problem of Global Concern. World Organization for Animal Health (OIE) ed. Eckert J, Gemmell MA, Meslin FX, Pawlowski ZS. Paris. pp. 229-239.

Gemmell, M.A., Roberts, M.G., Beard, T.C. and,. (2001). Quantitative epidemiology and transmission dynamics with special reference to Echinococcus granulosus. WHO/OIE Manual on Echinococcosis in Humans and Animals: a Public Health Problem of Global Concern. WorldWHO/OIE Manual on Echinococcosis in Humans and Animals: a Public Health Problem of Global Concern Organization for Animal Health (OIE) ed. Eckert J, Gemmell MA, Meslin FX, Pawlowski ZS. Paris. pp. 163-176.

Geyer, M., Wilpert, J., Wiech, T., Theilacker, C., Stubanus, M., Kramer-Zucker, A. et al. (2011). Rapidly progressive hepatic alveolar echinococcosis in an ABO-incompatible renal transplant recipient. Transplant Infectious Disease: An Official Journal of the Transplantation Society. 13, pp. 278-284. doi: 10.1111/j.1399-3062.2010.00583.x.

Ghoshal, A.G., Sarkar, S., Saha, K., Sarkar, U., Kundu, S., Chatterjee, S. et al. (2012). Hydatid lung disease: an analysis of five years cumulative data from Kolkata. The Journal of the Association of Physicians of India. 60, pp. 12-16.

Giraudoux, P. (1991). Utilisation de l'espace par les hôtes du ténia multiloculaire (Echinococcus multilocularis): conséquences épidémiologiques. Université de Bourgogne. Besançon.

Giraudoux, P., Raoul, F., Afonso, E., Ziadinov, I., Yang, Y., Li, L. et al. (2013). Transmission ecosystems of Echinococcus multilocularis in China and Central Asia. Parasitology. 140, pp. 1655-1666. doi: 10.1017/S0031182013000644.

Giraudoux, P., Raoul, F., Pleydell, D., Li, T., Han, X., Qiu, J. et al. (2013). Drivers of Echinococcus multilocularis transmission in China: small mammal diversity, landscape or climate?. PLoS neglected tropical diseases. 7, pp. e2045. doi: 10.1371/journal.pntd.0002045.

Goodfellow, M., Shaw, S. and Morgan, E. (2006). Imported disease of dogs and cats exotic to Ireland: Echinococcus multilocularis. Irish Veterinary Journal. 59, pp. 214-216. doi: 10.1186/2046-0481-59-4-214. 
Gori, F., Armua-Fernandez, M.T., Milanesi, P., Serafini, M., Magi, M., Deplazes, P. et al. (2015). The occurrence of taeniids of wolves in Liguria (northern Italy). International Journal for Parasitology: Parasites and Wildlife. 4, pp. 252-255. doi: 10.1016/j.ijppaw.2015.04.005.

Gottstein, B., Stojkovic, M., Vuitton, D.A., Millon, L., Marcinkute, A. and Deplazes, P. (2015). Threat of alveolar echinococcosis to public health-a challenge for Europe. Trends in Parasitology. 31, pp. 407-412. doi: 10.1016/j.pt.2015.06.001.

Graham, A.J., Danson, F.M., Giraudoux, P. and Craig, P.S. (2004). Ecological epidemiology: landscape metrics and human alveolar echinococossis. Acta Tropica. 91, pp. 267-278. doi: 10.1016/j.actatropica.2004.05.005.

Foodborne Diseases Epidemiology Reference Group (2015). WHO estimates of the global burden of foodborne diseases. WHO ed.

WHO Informal Working Group (2003). International classification of ultrasound images in cystic echinococcosis for application in clinical and field epidemiological settings. Acta Tropica. 85, pp. 253-261.

Gruener, B., Cretu, C.M., Brunetti, E., Menezes, C.N., Haerter, G., Grobusch, M.P. et al. (2008). Accelerated larval growth of Echinococcus spp in the immunodeficient host?. American Journal of Tropical Medicine and Hygiene. 79, pp. 118.

Guerra, D., Armua-Fernandez, M.T., Silva, M., Bravo, I., Santos, N., Deplazes, P. et al. (2013). Taeniid species of the Iberian wolf (Canis lupus signatus) in Portugal with special focus on Echinococcus spp. Int J Parasitol Parasites Wildl. 2, pp. 50-53. doi: 10.1016/j.ijppaw.2012.11.007.

Harandi, M.Fasihi, Budke, C.M. and Rostami, S. (2012). The monetary burden of cystic echinococcosis in Iran. PLoS neglected tropical diseases. 6, pp. e1915. doi: 10.1371/journal.pntd.0001915.

Hartnack, S., Budke, C.M., Craig, P.S., Jiamin, Q., Boufana, B., Campos-Ponce, M. et al. (2013). Latent-class methods to evaluate diagnostics tests for Echinococcus infections in dogs. PLoS neglected tropical diseases. 7, pp. e2068. doi: 10.1371/journal.pntd.0002068.

Havelaar, A.H., Kirk, M.D., Torgerson, P.R., Gibb, H.J., Hald, T., Lake, R.J. et al. (2015). World Health Organization Global Estimates and Regional Comparisons of the Burden of Foodborne Disease in 2010. PLoS medicine. 12, pp. e1001923. doi: 10.1371/journal.pmed.1001923.

Heath, D.D., Robinson, C., Shakes, T., Huang, Y., Gulnur, T., Shi, B. et al. (2012). Vaccination of bovines against Echinococcus granulosus (cystic echinococcosis). Vaccine. 30, pp. 3076-3081. doi: 10.1016/j.vaccine.2012.02.073.

Hegglin, D. and Deplazes, P. (2008). Control strategy for Echinococcus multilocularis. Emerging Infectious Diseases. 14, pp. 1626-1628. doi: 10.3201/eid1410.080522.

Hemphill, A., Stadelmann, B., Rufener, R., Spiliotis, M., Boubaker, G., Müller, J. et al. (2014). Treatment of echinococcosis: albendazole and mebendazole-what else?. Parasite (Paris, France). 21, pp. 70. doi: 10.1051/parasite/2014073.

Hercus, C.E., Williams, R.J., Gemmell, M.A. and Parnell, I.W. (1962). A warning that formalin is not a hydatid ovicide. Veterinary Record. 74, pp. 1515.

Horton, J. (2003). Albendazole for the treatment of echinococcosis. Fundamental \&amp; Clinical Pharmacology. 17, pp. 205-212.

Hotez, P.J., Alvarado, M., Basáñez, M.-.G., Bolliger, I., Bourne, R., Boussinesq, M. et al. (2014). The global burden of disease study 2010: interpretation and implications for the neglected tropical diseases. PLoS neglected tropical diseases. 8, pp. e2865. doi: 10.1371/journal.pntd.0002865.

Huang, L., Huang, Y., Wang, Q., Xiao, N., Yi, D., Yu, W. et al. (2011). An agent-based model for control strategies of Echinococcus granulosus. Vet. Parasitol. 179, pp. 84-91. doi: 10.1016/j.vetpar.2011.01.047.

Huang, Y., Yi, D.Y., Liu, L.L., Huang, L., Yu, W.J., Wang, Q. et al. (2014). Echinococcus infections in Chinese dogs: a 
comparison of coproantigen kits. Journal of Helminthology. 88, pp. 189-195. doi: 10.1017/S0022149X12000922.

Isaksson, M., Hagström, A., Armua-Fernandez, M.Teresa, Wahlström, H., Agren, E.O., Miller, A. et al. (2014). A semiautomated magnetic capture probe based DNA extraction and real-time PCR method applied in the Swedish surveillance of Echinococcus multilocularis in red fox (Vulpes vulpes) faecal samples. Parasites \&amp; Vectors. 7, pp. 583. doi: 10.1186/s13071-014-0583-6.

Ito, A., Urbani, C., Jiamin, Q., Vuitton, D.A., Dongchuan, Q., Heath, D.D. et al. (2003). Control of echinococcosis and cysticercosis: a public health challenge to international cooperation in China. Acta Tropica. 86, pp. 3-17.

Jacquot, M., Coeurdassier, M., Couval, G., Renaude, R., Pleydell, D., Truchetet, D. et al. (2013). Using long-term monitoring of red fox populations to assess changes in rodent control practices. Journal of Applied Ecology. 50, pp. 1406-1414.

Jiang, W., Liu, N., Zhang, G., Renqing, P., Xie, F., Li, T. et al. (2012). Specific detection of Echinococcus spp. from the Tibetan fox (Vulpes ferrilata) and the red fox (V. vulpes) using copro-DNA PCR analysis. Parasitology Research. 111, pp. 1531-1539. doi: 10.1007/s00436-012-2993-8.

Johansen, M.Vang and Penrith, M.-.L. (2009). Has culling been properly assessed as a valid and justified control intervention measure for zoonotic diseases?. PLoS neglected tropical diseases. 3, pp. e541. doi: 10.1371/journal.pntd.0000541.

Junghanss, T., da Silva, A.Menezes, Horton, J., Chiodini, P.L. and Brunetti, E. (2008). Clinical management of cystic echinococcosis: state of the art, problems, and perspectives. The American Journal of Tropical Medicine and Hygiene. 79, pp. 301-311.

Kadry, Z., Renner, E.C., Bachmann, L.M., Attigah, N., Renner, E.L., Ammann, R.W. et al. (2005). Evaluation of treatment and long-term follow-up in patients with hepatic alveolar echinococcosis. The British Journal of Surgery. 92, pp. 1110-1116. doi: 10.1002/bjs.4998.

Kaji, Y., Taniyama, H., Matsukawa, K., Okada, H., Tsunoda, S., Tagami, M. et al. (1993). First incidence of multilocular echinococcosis in a race horse in Japan. The Journal of Veterinary Medical Science / the Japanese Society of Veterinary Science. 55, pp. 869-870.

Kamiya, M., Ooi, H.K., Oku, Y., Okamoto, M., Ohbayashi, M. and Seki, N. (1987). Isolation of Echinococcus multilocularis from the liver of swine in Hokkaido, Japan. The Japanese Journal of Veterinary Research. 35, pp. 99-107.

Karamon, J. (2014). Detection of Echinococcus multilocularis in faeces by nested PCR with the use of diluted DNA samples. Polish Journal of Veterinary Sciences. 17, pp. 79-83.

Kawamura, N., Kamiyama, T., Sato, N., Nakanishi, K., Yokoo, H., Kamachi, H. et al. (2011). Long-term results of hepatectomy for patients with alveolar echinococcosis: a single-center experience. Journal of the American College of Surgeons. 212, pp. 804-812. doi: 10.1016/j.jamcollsurg.2011.02.007.

Kayacan, S.Mehmet, Vatansever, S., Temiz, S., Uslu, B., Kayacan, D., Akkaya, V. et al. (2008). Alveolar echinococcosis localized in the liver, lung and brain. Chinese Medical Journal. 121, pp. 90-92.

Kern, P., Grüner, B. and Wahlers, K. (2011). Diagnosis and course of echinococcocal diseases in the transplant setting. Transpl. Infect. Dis. Off. J. Transplant. Soc. 13, pp. 217-221. doi: 10.1111/j.1399-3062.2011.00643.x.

Kern, P. (2010). Clinical features and treatment of alveolar echinococcosis. Curr. Opin. Infect. Dis. 23, pp. 505-512. doi: 10.1097/QCO.0b013e32833d7516.

Kern, P., Grüner, B. and Wahlers, K. (2011). Diagnosis and course of echinococcocal diseases in the transplant setting. Transplant Infectious Disease: An Official Journal of the Transplantation Society. 13, pp. 217-221. doi: 10.1111/j.1399-3062.2011.00643.x.

Kern, P. (2006). Medical treatment of echinococcosis under the guidance of Good Clinical Practice (GCP/ICH). Parasitology International. 55 Suppl, pp. S273-282. doi: 10.1016/j.parint.2005.11.040. 
Kern, P., Bardonnet, K., Renner, E., Auer, H., Pawlowski, Z., Ammann, R.W. et al. (2003). European echinococcosis registry: human alveolar echinococcosis, Europe, 1982-2000. Emerging Infectious Diseases. 9, pp. 343-349. doi: 10.3201/eid0903.020341.

Kimura, H., Furuya, K., Kawase, S., Sato, C., Yamano, K., Takahashi, K. et al. (1999). Recent epidemiologic trends in alveolar echinococcosis prevalence in humans and animals in Hokkaido. Japanese Journal of Infectious Diseases. 52, pp. 117-120.

Klein, C., Liccioli, S. and Massolo, A. (2014). Egg intensity and freeze-thawing of fecal samples affect sensitivity of Echinococcus multilocularis detection by PCR. Parasitology Research. 113, pp. 3867-3873. doi: 10.1007/s00436-014-4055$\mathrm{x}$.

Knapp, J., Bart, J.M., Glowatzki, M.L., Ito, A., Gerard, S., Maillard, S. et al. (2007). Assessment of use of microsatellite polymorphism analysis for improving spatial distribution tracking of echinococcus multilocularis. Journal of Clinical Microbiology. 45, pp. 2943-2950. doi: 10.1128/JCM.02107-06.

Knapp, J., Bart, J.M., Maillard, S., Gottstein, B. and Piarroux, R. (2010). The genomic Echinococcus microsatellite EmsB sequences: from a molecular marker to the epidemiological tool. Parasitology. 137, pp. 439-449. doi: 10.1017/S0031182009991612.

Knapp, J., Staebler, S., Bart, J.M., Stien, A., Yoccoz, N.G., Drögemüller, C. et al. (2012). Echinococcus multilocularis in Svalbard, Norway: microsatellite genotyping to investigate the origin of a highly focal contamination. Infection, Genetics and Evolution: Journal of Molecular Epidemiology and Evolutionary Genetics in Infectious Diseases. 12, pp. 1270-1274. doi: 10.1016/j.meegid.2012.03.008.

Knapp, J., Gottstein, B., Saarma, U. and Millon, L. (2015). Taxonomy, phylogeny and molecular epidemiology of Echinococcus multilocularis: From fundamental knowledge to health ecology. Veterinary Parasitology. 213, pp. 85-91. doi: 10.1016/j.vetpar.2015.07.030.

Knapp, J., Millon, L., Mouzon, L., Umhang, G., Raoul, F., Ali, Z.Said et al. (2014). Real time PCR to detect the environmental faecal contamination by Echinococcus multilocularis from red fox stools. Veterinary Parasitology. 201, pp. 40-47. doi: 10.1016/j.vetpar.2013.12.023.

Knapp, J., Umhang, G., Poulle, M.-.L. and Millon, L. (2016). Development of a Real-Time PCR for a Sensitive One-Step Coprodiagnosis Allowing both the Identification of Carnivore Feces and the Detection of Toxocara spp. and Echinococcus multilocularis. Applied and Environmental Microbiology. 82, pp. 2950-2958. doi: 10.1128/AEM.03467-15.

Koch, S., Bresson-Hadni, S., Miguet, J.-.P., Crumbach, J.-.P., Gillet, M., Mantion, G.-.A. et al. (2003). Experience of liver transplantation for incurable alveolar echinococcosis: a 45-case European collaborative report. Transplantation. 75, pp. 856-863. doi: 10.1097/01.TP.0000054230.63568.79.

Konyaev, S.V., Yanagida, T., Ingovatova, G.M., Shoikhet, Y.N., Nakao, M., Sako, Y. et al. (2012). Molecular identification of human echinococcosis in the Altai region of Russia. Parasitology International. 61, pp. 711-714. doi: 10.1016/j.parint.2012.05.009.

Kouguchi, H., Matsumoto, J., Nakao, R., Yamano, K., Oku, Y. and Yagi, K. (2013). Characterization of a surface glycoprotein from Echinococcus multilocularis and its mucosal vaccine potential in dogs. PloS One. 8, pp. e69821. doi: 10.1371/journal.pone.0069821.

Labhardt, F. (1990). Der Rotfuchs. Naturgeschichte, Ökologie und Verhalten dieses erstaunlichen Jagdwildes.

Lagapa, J.T., Konno, K., Oku, Y., Nonaka, N. and Kamiya, M. (2001). Inhibitory effect of different UV lamps on the infectivity of taeniid eggs. Parasitology Research. 87, pp. 593-597.

Larrieu, E., Herrero, E., Mujica, G., Labanchi, J.Luis, Araya, D., Grizmado, C. et al. (2013). Pilot field trial of the EG95 vaccine against ovine cystic echinococcosis in Rio Negro, Argentina: early impact and preliminary data. Acta Tropica. 127, pp. 143-151. doi: 10.1016/j.actatropica.2013.04.009.

Larrieu, E., Mujica, G., Gauci, C.G., Vizcaychipi, K., Seleiman, M., Herrero, E. et al. (2015). Pilot Field Trial of the EG95 
Vaccine Against Ovine Cystic Echinococcosis in Rio Negro, Argentina: Second Study of Impact. PLoS neglected tropical diseases. 9, pp. e0004134. doi: 10.1371/journal.pntd.0004134.

Larrieu, E. and Zanini, F. (2012). Critical analysis of cystic echinococcosis control programs and praziquantel use in South America, 1974-2010. Revista Panamericana De Salud Pública = Pan American Journal of Public Health. 31, pp. 81-87.

Lass, A., Szostakowska, B., Myjak, P. and Korzeniewski, K. (2015). The first detection of Echinococcus multilocularis DNA in environmental fruit, vegetable, and mushroom samples using nested PCR. Parasitology Research. 114, pp. 4023-4029. doi: 10.1007/s00436-015-4630-9.

Laws, G.F. (1967). Chemical ovacidal measures as applied to Taenia hydatigena, Taenia ovis, Taenia pisiformis, and Echinococcus granulosus. Experimental Parasitology. 20, pp. 27-37.

Lawson, J.R. and Gemmell, M.A. (1990). Transmission of taeniid tapeworm eggs via blowflies to intermediate hosts. Parasitology. 100 Pt 1, pp. 143-146.

Lawson, J.R. and Gemmell, M.A. (1983). Hydatidosis and cysticercosis: the dynamics of transmission. Advances in Parasitology. 22, pp. 261-308.

Lawson, J.R. and Gemmell, M.A. (1985). The potential role of blowflies in the transmission of taeniid tapeworm eggs. Parasitology. 91 (Pt.1), pp. 129-143.

Lightowlers, M.W., Lawrence, S.B., Gauci, C.G., Young, J., Ralston, M.J., Maas, D. et al. (1996). Vaccination against hydatidosis using a defined recombinant antigen. Parasite Immunology. 18, pp. 457-462.

Lightowlers, M.W. (2006). Vaccines against cysticercosis and hydatidosis: foundations in taeniid cestode immunology. Parasitology International. 55 Suppl, pp. S39-43. doi: 10.1016/j.parint.2005.11.005.

Li, J., Wu, C., Wang, H., Liu, H., Vuitton, D.A., Wen, H. et al. (2014). Boiling sheep liver or lung for 30 minutes is necessary and sufficient to kill Echinococcus granulosus protoscoleces in hydatid cysts. Parasite (Paris, France). 21, 64, doi: 10.1051/parasite/2014064.

Liu, C.-.N., Lou, Z.-.Z., Li, L., Bin Yan, H.-., Blair, D., Lei, M.-.T. et al. (2015). Discrimination between E. granulosus sensu stricto, E. multilocularis and E. shiquicus Using a Multiplex PCR Assay. PLoS neglected tropical diseases. 9, pp. e0004084. doi: 10.1371/journal.pntd.0004084.

MacPherson, C.N.L. (2001). Epidemiology of Echinococcus granulosus in transhumant situations. WHO/OIE Manual on Echinococcosis in Humans and Animals: a Public Health Problem of Global Concern. World Organization for Animal Health (OIE) ed. Eckert J, Gemmell MA, Meslin FX, Pawlowski ZS. Paris. pp. 176-183.

Majorowski, M.M., Carabin, H., Kilani, M. and Bensalah, A. (2005). Echinococcosis in Tunisia: a cost analysis. Transactions of the Royal Society of Tropical Medicine and Hygiene. 99, pp. 268-278. doi: 10.1016/j.trstmh.2004.06.011.

Malik, A.A., Bari, S.Ul, Amin, R. and Jan, M. (2010). Surgical management of complicated hydatid cysts of the liver. World Journal of Gastrointestinal Surgery. 2, pp. 78-84. doi: 10.4240/wjgs.v2.i3.78.

Marcinkutè, A., Šarkūnas, M., Moks, E., Saarma, U., Jokelainen, P., Bagrade, G. et al. (2015). Echinococcus infections in the Baltic region. Veterinary Parasitology. 213, pp. 121-131. doi: 10.1016/j.vetpar.2015.07.032.

Martynenko, V.B., Maĭorova, L.A., Zorikhina, V.I. and Suvorina, V.I. (1983). [Epidemiology of alveolar hydatid disease in the taiga zone of Yakutia. Water as one of the possible intermediate factors in the transmission of the infestation]. Meditsinskaia Parazitologiia I Parazitarnye Bolezni. pp. 38-40.

Martynenko, V.B., Romanenko, N.A., Starkova, T.V., Loseva, T.A. and Ballad, N.E. (1986). [Epidemiological characteristics of echinococcosis in the population centers of the Yakutsk ASSR with different types of water supply]. Meditsinskaia Parazitologiia I Parazitarnye Bolezni. pp. 11-14.

Massolo, A., Liccioli, S., Budke, C. and Klein, C. (2014). Echinococcus multilocularis in North America: the great unknown. 
Parasite (Paris, France). 21, pp. 73. doi: 10.1051/parasite/2014069.

Mastrandrea, S., Stegel, G., Piseddu, T., Ledda, S. and Masala, G. (2012). A retrospective study on burden of human echinococcosis based on Hospital Discharge Records from 2001 to 2009 in Sardinia, Italy. Acta Tropica. 123, pp. 184-189. doi: 10.1016/j.actatropica.2012.05.004.

Mathis, A., Deplazes, P. and Eckert, J. (1996). An improved test system for PCR-based specific detection of Echinococcus multilocularis eggs. Journal of Helminthology. 70, pp. 219-222.

Mayor, P., Baquedano, L.E., Sanchez, E., Aramburu, J., Gomez-Puerta, L.A., Mamani, V.J. et al. (2015). Polycystic echinococcosis in Pacas, Amazon region, Peru. Emerging Infectious Diseases. 21, pp. 456-459. doi: 10.3201/eid2103.141197.

McManus, D.P. and Rishi, A.K. (1989). Genetic heterogeneity within Echinococcus granulosus: isolates from different hosts and geographical areas characterized with DNA probes. Parasitology. 99 pt 1, pp. 17-29.

Meymarian, E. and Schwabe, C.W. (1962). Host-parasite relationships in echinococcosis. VII. Resistance of the ova of Echinococcus granulosus to germicides. The American Journal of Tropical Medicine and Hygiene. 11, pp. 360-364.

Ming, R., Tolley, H.D., Andersen, F.L., Chai, J. and Chang, Q. (1992). Frequency distribution of Echinococcus granulosus in dog populations in the Xinjiang Uygur Autonomous Region, China. Veterinary Parasitology. 43, pp. 233-241.

Mobedi, I., Zare-Bidaki, M., Siavashi, M.,.., Kia, E. and Mahmoudi, M. (2013). Differential Detection of Echinococcus Spp. Copro-DNA by Nested-PCR in Domestic and Wild Definitive Hosts in Moghan Plain, Iran. Iranian Journal of Parasitology. 8, pp. 107-113.

Mong, J., Zhao, Y. and Beishanbo, A. (2011). Detection of Cryptosporidium in tap water in Xinjiang cities. Chinese Journal of Biology. 1, pp. 42-44.

Moro, P.L., Budke, C.M., Schantz, P.M., Vasquez, J., Santivañez, S.J. and Villavicencio, J. (2011). Economic impact of cystic echinococcosis in peru. PLoS neglected tropical diseases. 5, pp. e1179. doi: 10.1371/journal.pntd.0001179.

Murray, C.J.L., Barber, R.M., Foreman, K.J., Ozgoren, A.A., Abd-Allah, F., Abera, S.F. et al. (2015). Global, regional, and national disability-adjusted life years (DALYs) for 306 diseases and injuries and healthy life expectancy (HALE) for 188 countries, 1990-2013: quantifying the epidemiological transition. Lancet (London, England). 386, pp. 2145-2191. doi: 10.1016/S0140-6736(15)61340-X.

Murray, C.J.L., Vos, T., Lozano, R., Naghavi, M., Flaxman, A.D., Michaud, C. et al. (2012). Disability-adjusted life years (DALYs) for 291 diseases and injuries in 21 regions, 1990-2010: a systematic analysis for the Global Burden of Disease Study 2010. Lancet (London, England). 380, pp. 2197-2223. doi: 10.1016/S0140-6736(12)61689-4.

Nonaka, N., Iida, M., Yagi, K., Ito, T., Ooi, H.K., Oku, Y. et al. (1996). Time course of coproantigen excretion in Echinococcus multilocularis infections in foxes and an alternative definitive host, golden hamsters. International Journal for Parasitology. 26, pp. 1271-1278.

Oakley, G.A. (1991). Anthelmintics for cats and dogs. Anpar Books. Berkhamsted, Herts., England.

Oines, O., Isaksson, M., Hagström, A., Tavornpanich, S. and Davidson, R.K. (2014). Laboratory assessment of sensitive molecular tools for detection of low levels of Echinococcus multilocularis-eggs in fox (Vulpes vulpes) faeces. Parasites and Vectors. 7, pp. 246. doi: 10.1186/1756-3305-7-246.

Otero-Abad, B. and Torgerson, P.R. (2013). A systematic review of the epidemiology of echinococcosis in domestic and wild animals. PLoS neglected tropical diseases. 7, pp. e2249. doi: 10.1371/journal.pntd.0002249.

Pérez-Esandi, M.V., Colli, C.W. and Schantz, P.M. (1974). The ovicidal effect of selected chemicals against eggs of Echinococcus granulosus. Bulletin of the World Health Organization. 51, pp. 550-551.

Parnell, I.W. (1965). Some observations on taeniid ovicides: screening techniques, and the effects of some inorganic 
compounds. Journal of Helminthology. 39, pp. 257-272.

Parodi, P., Mantovani, A. and Seimenis, A. (2001). Public health education and training in control programmes. WHO/OIE Manual on Echinococcosis in Humans and Animals: a Public Health Problem of Global Concern. WHO/OIE Manual on Echinococcosis in Humans and Animals: a Public Health Problem of Global Concern ed. Eckert J, Gemmell MA, Meslin FX, Pawlowski ZS. Paris. pp. 239-245.

Pawlowski, Z.S., Eckert, J., Vuitton, D.A., Ammann, R.W., Kern, P., Craig, P.S. et al. (2001). Echinococcosis in humans: clinical aspects, diagnosis and treatment. WHO/OIE Manual on Echinococcosis in Humans and Animals: a Public Health Problem of Global Concern. World Organization for Animal Health (OIE) ed. Eckert J, Gemmell MA, Meslin FX, Pawlowski ZS. Paris. pp. 20-72.

Piarroux, M., Piarroux, R., Giorgi, R., Knapp, J., Bardonnet, K., Sudre, B. et al. (2011). Clinical features and evolution of alveolar echinococcosis in France from 1982 to 2007: results of a survey in 387 patients. Journal of Hepatology. 55, pp. 1025-1033. doi: 10.1016/j.jhep.2011.02.018.

Piarroux, M., Piarroux, R., Knapp, J., Bardonnet, K., Dumortier, J., Watelet, J. et al. (2013). Populations at risk for alveolar echinococcosis, France. Emerging Infectious Diseases. 19, pp. 721-728. doi: 10.3201/eid1905.120867.

Pleydell, D.R.J., Yang, Y.Rong, F. Danson, M., Raoul, F., Craig, P.S., McManus, D.P. et al. (2008). Landscape composition and spatial prediction of alveolar echinococcosis in southern Ningxia, China. PLoS neglected tropical diseases. 2 , pp. e287. doi: 10.1371/journal.pntd.0000287.

Ramesh, A., Lee, D.J., Wang, M.L., Hsu, J.P., Juang, R.S., Hwang, K.J. et al. (2006). Biofouling in membrane bioreactor. Separation Science and Technology. 41, pp. 1345-1370.

Ran, B., Shao, Y., Guo, Y., Yimiti, Y., Aji, T., Jia, J. et al. (2016). Surgical treatment of hepatic cystic echinococcosis in patients co-infected with HIV/AIDS. Journal of Helminthology. 90, pp. 125-128. doi: 10.1017/S0022149X15000188.

Raoul, F., Deplazes, P., Nonaka, N., Piarroux, R., Vuitton, D.A. and Giraudoux, P. (2001). Assessment of the epidemiological status of Echinococcus multilocularis in foxes in France using ELISA coprotests on fox faeces collected in the field. International Journal for Parasitology. 31, pp. 1579-1588.

Raoul, F., Hegglin, D. and Giraudoux, P. (2015). Trophic ecology, behaviour and host population dynamics in Echinococcus multilocularis transmission. Veterinary Parasitology. 213, pp. 162-171. doi: 10.1016/j.vetpar.2015.07.034.

Raoul, F., Michelat, D., Ordinaire, M., Décoté, Y., Aubert, M., Delattre, P. et al. (2003). Echinococcus multilocularis: secondary poisoning of fox population during a vole outbreak reduces environmental contamination in a high endemicity area. International Journal for Parasitology. 33, pp. 945-954.

Rausch, R.L. and Richards, S.H. (1971). Observations on parasite-host relationships of Echinococcus multilocularis Leuckart, 1863, in North Dakota. Canadian Journal of Zoology. 49, pp. 1317-1330.

Rehmann, P., Gröne, A., Gottstein, B., Völlm, J., Sager, H., Janovsky, M. et al. (2005). Detection of Echinococcus multilocularis infection in a colony of cynomolgus monkeys (Macaca fascicularis) using serology and ultrasonography. Journal of Veterinary Diagnostic Investigation: Official Publication of the American Association of Veterinary Laboratory Diagnosticians, Inc. 17, pp. 183-186.

Restrepo, A.M.Cadavid, Yang, Y.Rong, McManus, D.P., Gray, D.J., Giraudoux, P., Barnes, T.S. et al. (2016). The landscape epidemiology of echinococcoses. Infectious Diseases of Poverty. 5, pp. 13. doi: 10.1186/s40249-016-0109-x.

Reuter, S., Jensen, B., Buttenschoen, K., Kratzer, W. and Kern, P. (2000). Benzimidazoles in the treatment of alveolar echinococcosis: a comparative study and review of the literature. The Journal of Antimicrobial Chemotherapy. 46, pp. 451-456.

Reyes, M.M., Taramona, C.P., Saire-Mendoza, M., Gavidia, C.M., Barron, E., Boufana, B. et al. (2012). Human and canine echinococcosis infection in informal, unlicensed abattoirs in Lima, Peru. PLoS neglected tropical diseases. 6, pp. e1462. doi: 10.1371/journal.pntd.0001462.

Roberts, M.G., Lawson, J.R. and Gemmell, M.A. (1986). Population dynamics in echinococcosis and cysticercosis: 
mathematical model of the life-cycle of Echinococcus granulosus. Parasitology. 92 ( Pt 3), pp. 621-641.

Rojas, C.A.Alvarez, Romig, T. and Lightowlers, M.W. (2014). Echinococcus granulosus sensu lato genotypes infecting humans-review of current knowledge. International Journal for Parasitology. 44, pp. 9-18. doi: 10.1016/j.ijpara.2013.08.008.

Romig, T. (2009). Echinococcus multilocularis in Europe-state of the art. Veterinary Research Communications. 33 Suppl 1, pp. 31-34. doi: 10.1007/s11259-009-9244-1.

Romig, T., Ebi, D. and Wassermann, M. (2015). Taxonomy and molecular epidemiology of Echinococcus granulosus sensu lato. Veterinary Parasitology. 213, pp. 76-84. doi: 10.1016/j.vetpar.2015.07.035.

Said-Ali, Z., Grenouillet, F., Knapp, J., Bresson-Hadni, S., Vuitton, D.Angèle, Raoul, F. et al. (2013). Detecting nested clusters of human alveolar echinococcosis. Parasitology. 140, pp. 1693-1700. doi: 10.1017/S0031182013001352.

Sailer, M., Soelder, B., Allerberger, F., Zaknun, D., Feichtinger, H. and Gottstein, B. (1997). Alveolar echinococcosis of the liver in a six-year-old girl with acquired immunodeficiency syndrome. The Journal of Pediatrics. 130, pp. 320-323.

Sariözkan, S. and Yalçin, C. (2009). Estimating the production losses due to cystic echinococcosis in ruminants in Turkey. Veterinary Parasitology. 163, pp. 330-334. doi: 10.1016/j.vetpar.2009.04.032.

Satoh, M., Nakaya, K., Nakao, M., Xiao, N., Yamasaki, H., Sako, Y. et al. (2005). Short report: Echinococcus multilocularis confirmed on Kunashiri Island, 15 kilometers from the eastern part of Hokkaido, Japan. The American Journal of Tropical Medicine and Hygiene. 72, pp. 284-288.

Scharf, G., Deplazes, P., Kaser-Hotz, B., Borer, L., Hasler, A., Haller, M. et al. (2004). Radiographic, ultrasonographic, and computed tomographic appearance of alveolar echinococcosis in dogs. Veterinary Radiology \&amp; Ultrasound: The Official Journal of the American College of Veterinary Radiology and the International Veterinary Radiology Association. 45, pp. 411-418.

Schelling, U., Frank, W., Will, R., Romig, T. and Lucius, R. (1997). Chemotherapy with praziquantel has the potential to reduce the prevalence of Echinococcus multilocularis in wild foxes (Vulpes vulpes). Annals of Tropical Medicine and Parasitology. 91, pp. 179-186.

Schiller, E.L. (1954). Studies on the helminth fauna of Alaska. XIX. An experimental study on blowflow (Phormia regina) transmission of hydatid disease. Experimental Parasitology. 3, pp. 161-166.

Schroeder, I., Altreuther, G., Schimmel, A., Deplazes, P., Kok, D.J., Schnyder, M. et al. (2009). Efficacy of emodepside plus praziquantel tablets (Profender tablets for dogs) against mature and immature cestode infections in dogs. Parasitology Research. 105(Suppl 1), pp. S31-38. doi: 10.1007/s00436-009-1493-y.

Shaikenov, B.S., Rysmukhambetova, A.T., Massenov, B., Deplazes, P., Mathis, A. and Torgerson, P.R. (2004). Short report: the use of a polymerase chain reaction to detect Echinococcus granulosus (G1 strain) eggs in soil samples. The American Journal of Tropical Medicine and Hygiene. 71, pp. 441-443.

Soares, M.do Carmo P., de Souza, A.Junior Sou, Malheiros, A.Pinheiro, Nunes, H.Marceliano, Carneiro, L.Almeida, Alves, M.Moreira et al. (2014). Neotropical echinococcosis: second report of Echinococcus vogeli natural infection in its main definitive host, the bush dog (Speothos venaticus). Parasitology International. 63, pp. 485-487. doi: 10.1016/j.parint.2013.10.004.

Storandt, S.T., Virchow, D.R., Dryden, M.W., Hygnstrom, S.E. and Kazacos, K.R. (2002). Distribution and prevalence of Echinococcus multilocularis in wild predators in Nebraska, Kansas, and Wyoming. Journal of Parasitology. 88, pp. 420-422. doi: 10.1645/0022-3395(2002)088[0420:DAPOEM]2.0.CO;2.

Széll, Z., Sréter-Lancz, Z. and Sréter, T. (2014). Evaluation of faecal flotation methods followed by species-specific PCR for detection of Echinococcus multilocularis in the definitive hosts. Acta Parasitologica / Witold Stefański Institute of Parasitology, Warszawa, Poland. 59, pp. 331-336. doi: 10.2478/s11686-014-0248-9. 
Szostakowska, B., Lass, A., Kostyra, K., Pietkiewicz, H. and Myjak, P. (2014). First finding of Echinococcus multilocularis DNA in soil: preliminary survey in Varmia-Masuria Province, northeast Poland. Veterinary Parasitology. 203, pp. 73-79. doi: 10.1016/j.vetpar.2014.02.028.

Takahashi, K., Uraguchi, K., Hatakeyama, H., Giraudoux, P. and Romig, T. (2013). Efficacy of anthelmintic baiting of foxes against Echinococcus multilocularis in northern Japan. Veterinary Parasitology. 198, pp. 122-126. doi: 10.1016/j.vetpar.2013.08.006.

Tamarozzi, F., Vuitton, L., Brunetti, E., Vuitton, D.A. and Koch, S. (2014). Non-surgical and non-chemical attempts to treat echinococcosis: do they work?. Parasite Paris Fr. 21, pp. 75. doi: 10.1051/parasite/2014071.

Thakur, A.S., Prezioso, U. and Marchevsky, N. (1979). Echinococcus granulosus: ovicidal activity of praziquantel and bunamidine hydrochloride. Experimental Parasitology. 47, pp. 131-133.

Thompson, R.C. and Eckert, J. (1983). Observations on Echinococcus multilocularis in the definitive host. Zeitschrift Für Parasitenkunde (Berlin, Germany). 69, pp. 335-345.

Thompson, R.C.A., Kapel, C.M.O., Hobbs, R.P. and Deplazes, P. (2006). Comparative development of Echinococcus multilocularis in its definitive hosts. Parasitology. 132, pp. 709-716. doi: 10.1017/S0031182005009625.

Thompson, R.C. and Kumaratilake, L.M. (1985). Comparative development of Australian strains of Echinococcus granulosus in dingoes (Canis familiaris dingo) and domestic dogs (C.F. familiaris), with further evidence for the origin of the Australian sylvatic strain. International Journal for Parasitology. 15, pp. 535-542.

Thompson, R.C.A. and McManus, D.P. (2001). Aetiology: parasites and life-cycles. WHO/OIE Manual on Echinococcosis in Humans and Animals: a Public Health Problem of Global Concern. World Organization for Animal Health (OIE) ed. Eckert J, Gemmell MA, Meslin FX, Pawlowski ZS. Paris.

Torgerson, P.R. (2013). The emergence of echinococcosis in central Asia. Parasitology. 140, pp. 1667-1673. doi: 10.1017/S0031182013000516.

Torgerson, P.R., Carmona, C. and Bonifacino, R. (2000). Estimating the economic effects of cystic echinococcosis: Uruguay, a developing country with upper-middle income. Annals of Tropical Medicine and Parasitology. 94, pp. 703-713.

Torgerson, P.R. and Craig, P.S. (2009). Risk assessment of importation of dogs infected with Echinococcus multilocularis into the UK. The Veterinary Record. 165, pp. 366-368.

Torgerson, P.R., Dowling, P.M. and Abo-Shehada, M.N. (2001). Estimating the economic effects of cystic echinococcosis. Part 3: Jordan, a developing country with lower-middle income. Annals of Tropical Medicine and Parasitology. 95, pp. 595-603. doi: 10.1080/00034980120092534.

Torgerson, P.R., Karaeva, R.R., Corkeri, N., Abdyjaparov, T.A., Kuttubaev, O.T. and Shaikenov, B.S. (2003). Human cystic echinococcosis in Kyrgystan: an epidemiological study. Acta Tropica. 85, pp. 51-61.

Torgerson, P.R., Pilkington, J., Gulland, F.M. and Gemmell, M.A. (1995). Further evidence for the long distance dispersal of taeniid eggs. International Journal for Parasitology. 25, pp. 265-267.

Torgerson, P.R., Keller, K., Magnotta, M. and Ragland, N. (2010). The global burden of alveolar echinococcosis. PLoS neglected tropical diseases. 4, pp. e722. doi: 10.1371/journal.pntd.0000722.

Torgerson, P.R., Schweiger, A., Deplazes, P., Pohar, M., Reichen, J., Ammann, R.W. et al. (2008). Alveolar echinococcosis: from a deadly disease to a well-controlled infection. Relative survival and economic analysis in Switzerland over the last 35 years. Journal of Hepatology. 49, pp. 72-77. doi: 10.1016/j.jhep.2008.03.023.

Torgerson, P.R., MacPherson, C.N.L. and Vuitton, D.A. (2011). Cystic Echinococcosis. Oxford Textbook on Zoonoses (2nd Ed). Biology, clinical practice, and public control. Oxford University Press ed. Palmer SR, Soulsby L, Torgerson P, Brown DWG. Oxford. pp. 1-62. 
Trachsel, D., Deplazes, P. and Mathis, A. (2007). Identification of taeniid eggs in the faeces from carnivores based on multiplex PCR using targets in mitochondrial DNA. Parasitology. 134, pp. 911-920. doi: 10.1017/S0031182007002235.

Ueno, M., Kuroda, N., Yahagi, K., Ohtaki, T. and Kawanaka, M. (2012). Analysis of antibody responses by commercial western blot assay in horses with alveolar echinococcosis. The Journal of Veterinary Medical Science / the Japanese Society of Veterinary Science. 74, pp. 813-815.

Umhang, G., Comte, S., Raton, V., Hormaz, V., Boucher, J.-.M., Favier, S. et al. (2014). Echinococcus multilocularis infections in dogs from urban and peri-urban areas in France. Parasitology Research. 113, pp. 2219-2222. doi: 10.1007/s00436-014-3875-z.

Umhang, G., Lahoreau, J., Hormaz, V., Boucher, J.-.M., Guenon, A., Montange, D. et al. (2016). Surveillance and management of Echinococcus multilocularis in a wildlife park. Parasitology International. 65, pp. 245-250. doi: 10.1016/j.parint.2016.01.008.

van Kesteren, F., Qi, X., Tao, J., Feng, X., Mastin, A., Craig, P.S. et al. (2015). Independent evaluation of a canine Echinococcosis Control Programme in Hobukesar County, Xinjiang, China. Acta Tropica. 145, pp. 1-7. doi: 10.1016/j.actatropica.2015.01.009.

Veit, P., Bilger, B., Schad, V., Schäfer, J., Frank, W. and Lucius, R. (1995). Influence of environmental factors on the infectivity of Echinococcus multilocularis eggs. Parasitology. 110 ( Pt 1), pp. 79-86.

Venegas, J., Espinoza, S. and Sánchez, G. (2014). [Estimation of costs caused by cystic echinococcosis]. Revista Médica De Chile. 142, pp. 1023-1033. doi: 10.4067/S0034-98872014000800010.

Viel, J.F., Giraudoux, P., Abrial, V. and Bresson-Hadni, S. (1999). Water vole (Arvicola terrestris scherman) density as risk factor for human alveolar echinococcosis. The American Journal of Tropical Medicine and Hygiene. 61, pp. 559-565.

Vizcaychipi, K.A., Helou, M., Dematteo, K., Macchiaroli, N., Cucher, M., Rosenzvit, M. et al. (2013). [First report of Echinococcus vogeli in a paca in Misiones province, Argentina]. Revista Argentina De Microbiología. 45, pp. 169-173.

Vuitton, D.A., Azizi, A., Richou, C., Vuitton, L., Blagosklonov, O., Delabrousse, E. et al. (2016). Current interventional strategy for the treatment of hepatic alveolar echinococcosis. Expert Rev. Anti Infect. Ther. 14, pp. 1179-1194. doi: 10.1080/14787210.2016.1240030.

Vuitton, D.A., Demonmerot, F., Knapp, J., Richou, C., Grenouillet, F., Chauchet, A. et al. (2015). Clinical epidemiology of human AE in Europe. Veterinary Parasitology. 213, pp. 110-120. doi: 10.1016/j.vetpar.2015.07.036.

Vuitton, D.A., Zhou, H., Bresson-Hadni, S., Wang, Q., Piarroux, M., Raoul, F. et al. (2003). Epidemiology of alveolar echinococcosis with particular reference to China and Europe. Parasitology. 127 Suppl, pp. S87-107.

Vuitton, D.A. and Bresson-Hadni, S. (Submitted). Alveolar echinococcosis: evaluation of therapeutic strategies. Expert Opinion on Orphan Drugs. 2, pp. 67-86.

Vuitton, D.Angèle and Gottstein, B. (2010). Echinococcus multilocularis and its intermediate host: a model of parasite-host interplay. Journal of Biomedicine \&amp; Biotechnology. 2010, pp. 923193. doi: 10.1155/2010/923193.

Vuitton, D.Angèle, Zhang, S.Ling, Yang, Y., Godot, V., Beurton, I., Mantion, G. et al. (2006). Survival strategy of Echinococcus multilocularis in the human host. Parasitology International. 55 Suppl, pp. S51-55. doi: 10.1016/j.parint.2005.11.007.

Wang, Q., Vuitton, D.A., Qiu, J., Giraudoux, P., Xiao, Y., Schantz, P.M. et al. (2004). Fenced pasture: a possible risk factor for human alveolar echinococcosis in Tibetan pastoralist communities of Sichuan, China. Acta Tropica. 90, pp. 285-293. doi: 10.1016/j.actatropica.2004.02.004.

Wang, Q., Vuitton, D.A., Xiao, Y., Budke, C.M., Campos-Ponce, M., Schantz, P.M. et al. (2006). Pasture types and Echinococcus multilocularis, Tibetan communities. Emerging Infectious Diseases. 12, pp. 1008-1010. 
Wen, H., Tian, W.L., Zou, P.F. and Xiang, M.X. (1992). A rare case of mixed cystic and alveolar hydatidosis. Transactions of the Royal Society of Tropical Medicine and Hygiene. 86, pp. 290-291.

Wen, H., Zhang, Y-lou., Bart, J.-.M., Giraudoux, P., Vuitton, D.A., Ma, X-dong. et al. (2006). Mixed infection of Echinococcus granulosus and Echinococcus multilocularis in dog. Chinese Journal of Parasitology and Parasitic Diseases. 24, pp. 10-13.

WHO-Informal Working Group on Echinococcosis (2001). PAIR: puncture, aspiration, injection, reaspiration: an option for the treatment of cystic echinococcosis.

Williams, J.F. and Colli, C.W. (1972). Influence of ionizing irradiation on infectivity of eggs of Echinococcus granulosus in laboratory rodents. The Journal of Parasitology. 58, pp. 427-430.

Wilson, J.F., Rausch, R.L., McMahon, B.J. and Schantz, P.M. (1992). Parasiticidal effect of chemotherapy in alveolar hydatid disease: review of experience with mebendazole and albendazole in Alaskan Eskimos. Clinical Infectious Diseases: An Official Publication of the Infectious Diseases Society of America. 15, pp. 234-249.

Wilson, J.F., Rausch, R.L. and Wilson, F.R. (1995). Alveolar hydatid disease. Review of the surgical experience in 42 cases of active disease among Alaskan Eskimos. Annals of Surgery. 221, pp. 315-323.

Xiao, N., Nakao, M., Qiu, J., Budke, C.M., Giraudoux, P., Craig, P.S. et al. (2006). Dual infection of animal hosts with different Echinococcus species in the eastern Qinghai-Tibet plateau region of China. The American Journal of Tropical Medicine and Hygiene. 75, pp. 292-294.

Xiao, N., Qiu, J., Nakao, M., Li, T., Yang, W., Chen, X. et al. (2005). Echinococcus shiquicus n. sp., a taeniid cestode from Tibetan fox and plateau pika in China. International Journal for Parasitology. 35, pp. 693-701. doi: 10.1016/j.ijpara.2005.01.003.

Xie, P. (2016). Surveillance result analysis of environmental hygiene in villages in Beipiao city, Liaoning from 2014 to 2015. Chinese Journal of Integrative Medicine. 23, pp. 149-152.

Yamamoto, N., Kishi, R., Katakura, Y. and Miyake, H. (2001). Risk factors for human alveolar echinococcosis: a case-control study in Hokkaido, Japan. Annals of Tropical Medicine and Parasitology. 95, pp. 689-696. doi: 10.1080/00034980120103252.

Yang, Y.R., Vuitton, D.A., Jones, M.K., Craig, P.S. and McManus, D.P. (2005). Brain metastasis of alveolar echinococcosis in a hyperendemic focus of Echinococcus multilocularis infection. Transactions of the Royal Society of Tropical Medicine and Hygiene. 99, pp. 937-941. doi: 10.1016/j.trstmh.2005.04.020.

Yang, Y.R., Williams, G.M., Craig, P.S., Sun, T., Yang, S.K., Cheng, L. et al. (2006). Hospital and community surveys reveal the severe public health problem and socio-economic impact of human echinococcosis in Ningxia Hui Autonomous Region, China. Tropical medicine \&amp; international health: TM \&amp; IH. 11, pp. 880-888. doi: $10.1111 /$ j.1365-3156.2006.01633.x.

Yang, Y.Rong, Craig, P.S., Vuitton, D.A., Williams, G.M., Sun, T., Liu, T.Xi et al. (2008). Serological prevalence of echinococcosis and risk factors for infection among children in rural communities of southern Ningxia, China. Tropical medicine \&amp; international health. 13, pp. 1086-1094. doi: 10.1111/j.1365-3156.2008.02101.x.

Yang, Y.Rong, Liu, X.Zhou, Vuitton, D.A., Bartholomot, B., Wang, Y.Hai, Ito, A. et al. (2006). Simultaneous alveolar and cystic echinococcosis of the liver. Transactions of the Royal Society of Tropical Medicine and Hygiene. 100, pp. 597-600. doi: 10.1016/j.trstmh.2005.09.016.

Yang, Y.Rong, Sun, T., Li, Z., Zhang, J., Teng, J., Liu, X. et al. (2006). Community surveys and risk factor analysis of human alveolar and cystic echinococcosis in Ningxia Hui Autonomous Region, China. Bulletin of the World Health Organization. 84, pp. 714-721.

Zhang, W. and McManus, D.P. (2008). Vaccination of dogs against Echinococcus granulosus: a means to control hydatid disease?. Trends in Parasitology. 24, pp. 419-424. doi: 10.1016/j.pt.2008.05.008. 
Zhang, W., Zhang, Z., Shi, B., Li, J., You, H., Tulson, G. et al. (2006). Vaccination of dogs against Echinococcus granulosus, the cause of cystic hydatid disease in humans. The Journal of Infectious Diseases. 194, pp. 966-974. doi: 10.1086/506622.

Zingg, W., Renner-Schneiter, E.C., Pauli-Magnus, C., Renner, E.L., van Overbeck, J., Schläpfer, E. et al. (2004). Alveolar echinococcosis of the liver in an adult with human immunodeficiency virus type-1 infection. Infection. 32, pp. 299-302. 